\title{
A NEW GENERATION OF TROPICAL CYCLONE SIZE MEASUREMENTS FROM SPACE
}

\author{
N. Reul, B. Chapron, E. Zabolotskikh, C. Donlon, A. Mouche, J. Tenerelli, F. Collard, \\ J. F. Piolle, A. Fore, S. Yueh, J. Cotton, P. Francis, Y. Quilfen, and V. Kudryavtsev
}

\author{
Combined microwave brightness temperature measurements from recent \\ $\mathrm{L}$ - and dual C-band satellite radiometers provide new estimates of \\ surface wind speed structure in tropical cyclones.
}

0 bservations of ocean surface wind speed field structures associated with tropical cyclones (TCs) are important to a variety of public, private, and governmental stakeholders and applications. Global tropical cyclone warning centers [e.g., at the National Hurricane Center (NHC), the Central Pacific Hurricane Center (CPHC), or the Joint Typhoon Warning Center (JTWC)] routinely estimate an ensemble of parameters describing the structure of surface wind fields in TCs as part of their TC advisory and warning process. These include the maximum sustained wind (MSW), defined as the maximum 1-min-average wind speed at the altitude of $10 \mathrm{~m}$; the radius of maximum wind (RMW); and the maximum radial extent of significant wind speed thresholds. These estimates are typically referred to collectively as wind radii and come in the form of the maximum radial extent of 34-, 50-, and 64-kt $\left(1 \mathrm{kt}=0.514 \mathrm{~m} \mathrm{~s}^{-1}\right)$ winds in geographic quadrants (i.e., in the northeast, southeast, southwest, and northwest directions). These distances are reported in units of nautical miles ( $\mathrm{n} \mathrm{mi}$, where $1 \mathrm{n} \mathrm{mi}=1.85 \mathrm{~km}$ ).

Satellite data have been a major source of information to infer those parameters, and today, the Dvorak technique is the primary satellite method for estimating MSW in TCs based on cloud pattern recognition from visible (VIS) and infrared (IR) satellite images [see Dvorak (1975) and Velden et al. (2006) for a review]. There are other methods (e.g., Kidder et al. 1978), but the Dvorak technique continues to be the standard and most-successful method for estimating TC intensity where aircraft reconnaissance is not available (all tropical regions outside the North Atlantic and Caribbean Sea) although it has known limitations and flaws (e.g., Velden et al. 2006). In particular, the Dvorak method is a rather indirect way to get the 1-min sustained wind, as wind is not directly measured. Systems providing a more direct measure of wind at the surface appear to have a greater potential in accurately defining wind radii and intensities.

Besides cloud/feature tracked winds (Holmlund et al. 2001; Velden et al. 2005), satellite observations of high winds further include high wind scatterometry (Quilfen et al. 1998; Fernandez et al. 2006; Brennan et al. 2009; Quilfen et al. 2010; Soisuvarn et al. 2013; Chou et al. 2013; Van Zadelhoff et al. 2014). In addition to these remotely sensed wind vectors, there are several operational tools specifically designed to estimate TC vortex structure. These include techniques that estimate wind radii directly from multichannel microwave sounders operating 
in the range $23-184 \mathrm{GHz}$ (Demuth et al. 2004, 2006), such as the sensors on board the Advanced Microwave Sounding Unit (AMSU) satellites, and methods that estimate the flight-level winds using information derived from IR satellite imagery, TC intensity, and TC motion (Mueller et al. 2006; Kossin et al. 2007; Knaff et al. 2015). Each of these methods and observations has its own weaknesses (Knaff et al. 2016). As a result, errors in operational (and best tracked) wind radii estimates can at times be as large as $25 \%-40 \%$ of the radii themselves [see Knaff and Harper (2010) or Knaff and Sampson (2015)]. The average uncertainty of the size best tracks (maximum extent of 34-, 50-, and 64-kt wind radii) was found to be almost invariant with respect to intensity [see Table 2 in Landsea and Franklin (2013)] but strongly related to the measurement capabilities. Average uncertainties from satellite-only measurements (i.e., no aircraft data) regardless of storm intensity for the gale (34 kt), storm (50 kt), and hurricane ( $64 \mathrm{kt})$ radii are of $\sim 40,30$, and $24.5 \mathrm{n} \mathrm{mi}$. Better and more frequent estimates of these key structural parameters of TC surface wind fields in near-real time (NRT) lies at the heart of improved tropical cyclone forecasting and warning capabilities.

Passive microwave imagery (MI) in the lowest frequencies below $30 \mathrm{GHz}$, while not used to explicitly estimate intensity, is an important tool utilized to examine TC structural features, and assists in the Dvorak technique by aiding center fixes. Microwave brightness temperature of the ocean is strongly

Affiliations: Reul, Chapron, Mouche, Piolle, and QuilfenLaboratoire d'Océanographie Physique et Spatiale, Institut Français de Recherche et d'Exploitation de la Mer, Brest, France; ZABOLOTSKIKH AND KUDRYAVTSEV-Satellite Oceanography Laboratory, Russian State Hydrometeorological University, St. Petersburg, Russia; Donlon-Mission Science Division, Earth Observation Programme Directorate, ESTEC, European Space Agency, Noordwijk, Netherlands; Tenerelli AND Collard-OceanDataLab, Plougonvelin, France; FORE AND YUEH-Jet Propulsion Laboratory, Pasadena, California; CotTON-Satellite Winds and Active Sensing Group, Met Office, Exeter, United Kingdom; FrancIs-Satellite Imagery Applications Group, Met Office, Exeter, United Kingdom CORRESPONDING AUTHOR: Nicolas Reul,

nicolas.reul@ifremer.fr

The abstract for this article can be found in this issue, following the table of contents.

DOI:10.II75/BAMS-D-I5-0029I.I

In final form 8 March 2017

(02017 American Meteorological Society

For information regarding reuse of this content and general copyright information, consult the AMS Copyright Policy. dependent on variations in surface emissivity associated with increasing foam coverage due to whitecap and streaks induced by wave breaking, wind shear of the wave crest (Holthuijsen et al. 2012; Nordberg et al. 1971; Ross and Cardone 1974; Webster et al. 1976), and the distribution of foam formation and seaspray layer thicknesses (Anguelova and Gaiser 2012; Camps et al. 2005; Reul and Chapron 2003; Raizer 2007). The continuously increasing "whitening" of the sea surface as the wind speed intensifies above $\sim 10-12 \mathrm{~m} \mathrm{~s}^{-1}$ induces a continuous growth of the radio-brightness emission from the sea surface, as observed by a low-frequency microwave radiometer in storms. Provided atmospheric (rain, cloud liquid water, vapor, oxygen, etc.) and sea-spray droplets contributions can be well accounted for, the measured radio-brightness contrast change can be related to surface wind speed. The step frequency microwave radiometer (SFMR) operating at $\mathrm{C}$ band $(4-8 \mathrm{GHz})$, which is NOAA's primary airborne sensor for measuring tropical cyclone surface wind speeds (Uhlhorn et al. 2007), is based on this principle.

Until very recently, multifrequency ( $\sim 6.9$ to $>89 \mathrm{GHz}$ ) satellite microwave radiometers [e.g., Special Sensor Microwave Imager (SSM/I), Special Sensor Microwave Imager/Sounder (SSMIS), Tropical Rainfall Measuring Mission (TRMM) Microwave Imager (TMI), TRMM, Advanced Microwave Scanning Radiometer (AMSR), AMSU, Conical Microwave Imager/Sounder (CMIS), Advanced Microwave Scanning Radiometer for Earth Observing System (EOS) (AMSR-E), and WindSat] all operated at frequencies higher, or equal to, $\mathrm{C}$ band and, if available, only acquired data from one single $\mathrm{C}$-band channel. These satellite instruments are very efficient tools to infer cloud liquid water, water vapor, wind speed, rain rate, and sea surface temperature (SST) in certain conditions typically below hurricane-force winds. However, at these frequencies, atmospheric absorption, emission, and scattering associated with high cloud liquid water content and precipitation prevalent in cyclones can have a large impact on brightness temperatures. Consequently, it is challenging to obtain accurate ocean surface wind and whitecap properties beneath tropical cyclones at these frequencies. The measurement of ocean surface wind speeds during precipitation events has been a long-standing problem for satellite passive microwave radiometers. While algorithms have been developed that are able to measure ocean surface wind speeds with an accuracy of $\sim 2 \mathrm{~m} \mathrm{~s}^{-1}$, in rain-free conditions [e.g., see Bettenhausen et al. (2006) and discussions in Meissner and Wentz (2009)], unfortunately, they 
break down completely as soon as light rain is present. For accurate retrievals of wind speeds when precipitation is present it is essential to use different frequencies, whose spectral signatures make it possible to find $\mathrm{X}$ - and C-band channel combinations that yield brightness temperature with sufficient sensitivity to wind speed and low sensitivity to rain (Shibata 2006; Yueh 2008; Meissner and Wentz 2009; El-Nimri et al. 2010; Saitoh and Shibata 2010; Mai et al. 2016; Zhang et al. 2016). This multifrequency channel combination principle also led to the development of the SFMR instrument (Harrington 1980), which measures the brightness temperature of the ocean surface using six distinct close-by C-band frequencies, which permit the simultaneous retrieval of both rain rate and surface wind speed.

For extreme tropical cyclone conditions, a new generation of microwave satellite sensors-namely, the European Space Agency (ESA) Soil Moisture and Ocean Salinity (SMOS), the National Aeronautics and Space Administration (NASA) Soil Moisture Active Passive (SMAP), and the Japan Aerospace Exploration Agency (JAXA) Advanced Microwave Scanning Radiometer 2 (AMSR-2) missions-can now provide complementary surface wind speed sensing capabilities. Indeed, these sensors operate either at a significantly lower microwave frequency than their predecessors, which is the case for SMOS and SMAP that operate at $1.4 \mathrm{GHz}$ (L band), or are equipped with dual-frequency C-band channels (AMSR-2). Owing to the rather long electromagnetic wavelength at $\mathrm{L}$ band $(21 \mathrm{~cm})$, atmospheric attenuation and emission due to heavy rain prevalent in TCs have a negligible impact on Earth surface upwelling signals measured both by SMOS and SMAP (Reul et al. 2012, 2016). As already demonstrated, negligible signal sensitivity to rain combined with significant sensitivity to increasing wind allows the determination of reliable outer wind speed structure in TCs from L-band passive sensor data [see Reul et al. $(2012,2016)$ and Yueh et al. (2016)]. Improved all-weather wind speed and rain retrieval algorithms have also recently been developed by Zabolotskikh et al. (2013, 2014, 2015, 2016), taking advantage of the dual C-band channel capability on board AMSR-2. All three sensors have rather coarse spatial resolution, on the order of $\sim 40$ $50 \mathrm{~km}$, which can limit their ability to systematically provide reliable inner-core wind structure in TCs (e.g., RMW or MSW). Nevertheless, these three sensors provide additional information on the outer wind structure in TCs such as the important wind radii at 34,50 , and $64 \mathrm{kt}$, complementing the ensemble of observation already performed by currently orbiting scatterometers [ASCAT, OceanSat-2, and Haiyang-2A (HY-2A)] and other multifrequency radiometers (SSM/I, WindSat, and AMSU). Thanks to their large swaths (width of $\sim 1,000 \mathrm{~km}$ for SMOS and SMAP and 1,450 km for AMSR-2), observations are obtained very regularly during the storm's lifetime to possibly complement the ensemble of observations used by tropical cyclone centers and forecasters.

To illustrate our purpose, we first consider how the estimated gale-force wind radii $(34 \mathrm{kt})$ from SMOS data compare with the best track estimates (Jarvinen et al. 1984) for the long-lived category 1 hurricane Nadine: Nadine developed in the North Atlantic in 2012 and SMOS intercepted it 20 times.

Systematic comparisons between SMOS, AMSR-2, and best track estimates of 34-, 50-, and 64-kt wind radii are then provided for a large ensemble of data in TCs that developed in the North Atlantic and east Pacific during 2010-15.

Finally, we further provide the structural parameters estimated from the three combined satellite datasets acquired over three category 4 hurricanes that developed concomitantly during AugustSeptember 2015 in the east and central Pacific. Comparisons of the satellite-estimated structural wind field parameters are given with respect to best track. The complementarity of the new wind products to traditional satellite measurements of wind speed and their limitations are discussed in the last section.

\section{MEASURING HIGH WIND SPEED WITH THE SMOS AND SMAP L-BAND RADIOMETERS. SMOS (Kerr et al. 2010) and} SMAP (Entekhabi et al. 2014) radiometers (see Fig. 1) both operate at $\mathrm{L}$ band $(\sim 1.4 \mathrm{GHz}, 21$-cm wavelength), a protected frequency primarily chosen to allow global measurements of soil moisture and ocean surface salinity from space (Mecklenburg et al. 2016). SMOS and SMAP were launched late 2009 and early 2015, respectively. Both sensors provide L-band brightness temperature imaging of Earth over a $\sim 1,000-\mathrm{km}$-wide swath at about $\sim 40-\mathrm{km}$ nominal resolution, and with global coverage in about 3 days. SMOS is a fully polarized interferometric radiometer and acquires multi-incidence angle $\left(0^{\circ}-60^{\circ}\right)$ images of an Earth target. The SMAP instrument is a real aperture radiometer and probes Earth brightness at a fixed incidence angle of $\sim 40^{\circ}$, at two opposite azimuthal directions (fore and aft views).

It was first demonstrated (Reul et al. 2012, 2016) that SMOS passive measurements offer new and unique opportunities to complement existing ocean satellite high wind observations in TCs and severe 
weather. Upwelling radiation at $1.4 \mathrm{GHz}$ is indeed significantly less affected by rain and atmospheric effects than at higher microwave frequencies. In particular, the absorption due to rain of upwelling radiations is two orders of magnitude larger at C-band frequencies than at L band [see Fig. 2 in Reul et al. (2012)]. In Reul et al. (2016), the SMOS-measured L-band storm-induced microwave brightness temperature excess has been related to surface wind speed. Using a large ensemble of collocated SFMR aircraft winds (Uhlhorn et al. 2007), and Hurricane Research Division (HRD) Real-time Hurricane Wind Analysis System ( $\mathrm{H}^{\star} \mathrm{W}$ ind) analyses (Powell et al. 1998), collected for an ensemble of storms between 2010 and 2015 , the inferred geophysical model function (GMF) is a quadratic relationship of the surface wind speed at a height of $10 \mathrm{~m}$ (U10). Validation of the inferred surface wind speed products shows that surface wind speed can effectively be retrieved from SMOS data using this GMF with an RMS error on the order of $5 \mathrm{~m} \mathrm{~s}^{-1}(\sim 10 \mathrm{kt})$ up to $\sim 50 \mathrm{~m} \mathrm{~s}^{-1}(\sim 100 \mathrm{kt})$. Similar results involving SMAP data and a slightly different GMF were recently reported by Yueh et al. (2016).

Uncertainty in the SMOS-retrieved wind speed must be minimized from an ensemble of instrumental and geophysical issues. These include radiometric

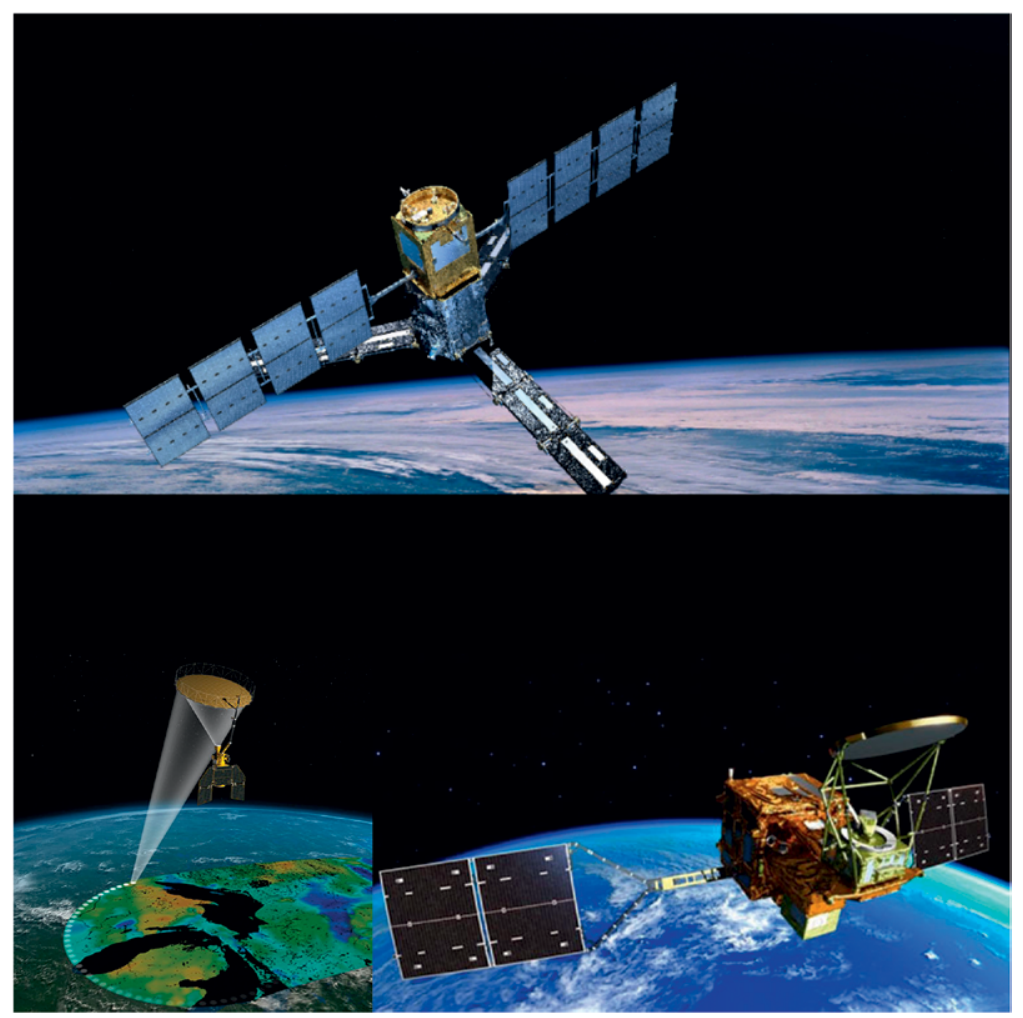

FIG. I. Artistic views of the (top) ESA SMOS, (bottom left) NASA SMAP, and (bottom right) JAXA AMSR-2 satellite missions. uncertainties: badly corrected residual solar effects on the brightness temperature images, varying noise level depending on the pixel location within the field of view, and brightness temperature image reconstruction biases (e.g., seasonal, orbital, at land-sea transitions). Most troublesome is the fact that, although the SMOS radiometer frequency of $1.413 \mathrm{GHz}$ belongs to a frequency band $(1,400-1,427 \mathrm{MHz})$ protected by international regulations, contamination by unwanted out-of-band emissions from poorly maintained transmitters and possibly illegally operating emitters (radars, telecommunications) compromise the quality of the SMOS retrievals in some areas (Oliva et al. 2016). A high number of radio-frequency interference (RFI) events are observed worldwide and particularly impact the quality of the SMOSretrieved winds along the coasts of Asia. As SMOS, launched in 2009, was the first satellite to operate in L band, it does not have any onboard hardware/ software to filter RFI. This issue is significantly less important for SMAP, as it is equipped with onboard frequency-/time-domain-based RFI filters. Finally, some geophysical contributions to the observed brightness signal at $\mathrm{L}$ band in storm conditions are poorly known and/or accounted for in the retrieval algorithms. These include uncertainties on the sea surface salinity (SSS) value under TCs, which is determined in our algorithm using the SMOS-retrieved SSS averaged over the previous week before each storm passage. SSS during storm passage is however modified from prestorm conditions owing to the intense vertical mixing at the base of the oceanic mixed layer that is generated concomitantly in the wake of these storms by the TC-induced inertial current shear. The vertical current shear generally upwells colder and saltier subsurface waters from below the mixed layer (Price 1981). The latter rapidly mixes with the freshwater that falls from the atmosphere into the upper ocean: the upper-ocean salinity found under these extremes is therefore the resultant of these two counteracting effects. Jourdain et al. (2013) found that surface salinity usually increases in the wake of cyclones because vertical mixing entrains subsurface water that is, on average, saltier than surface water in 
convective regions associated with cyclonic activity. The mixing effect overwhelms the dilution effect of rain freshwater: the cyclone "cold wake" is hence also generally a "salty wake." Characterizing the actual variability of SSS under all TCs nevertheless remains a challenge as SSS cannot be systematically obtained in these conditions from currently available observation platforms (in situ, satellite). In addition, SSS can change very rapidly at targets located in highly dynamical and variable areas (such as the Amazon or Mississippi River plumes). Uncertainties on SSS and also inaccuracies in the sea surface temperature retrieved from MW observations under heavy precipitation (Wentz et al. 2000) and the potential impact of intense rain and ice clouds [while much weaker than at $\mathrm{C}$ band, Reul et al. (2016) identified a potential effect of intense rain and ice clouds on SMOS L-band data] all contribute to the remaining uncertainties on SMOS- and SMAP-retrieved surface winds in TCs.

From a strict sensor physics point of view, L-band radiometers do not directly measure surface winds. Radio-brightness sensitivity is mostly controlled by foam formation structure changes at the ocean surface under wind-wave forcing conditions. The respective contributions of wind and waves to the measured excess brightness signal stay poorly known. Variations in sea states possibly found for a fixed radial wind speed in the different storm quadrants (Kudryavtsev et al. 2015) likely contributes to uncertainties on the retrieved surface wind and wind radii (Uhlhorn et al. 2007).

\section{MEASURING HIGH WIND SPEEDS WITH} THE DUAL C-BAND CHANNELS OF AMSR-2. To properly evaluate and possibly compensate for precipitation and other atmospheric contributions to the brightness changes observed by C-band radiometers in TCs, the wind speed retrieval algorithm requires measurements from several $\mathrm{C}$ - or $\mathrm{X}$-band frequency channels. Small changes in the respective contribution of wind and rain to the signal measured by each channel can then be used to accurately infer both quantities (Klotz and Uhlhorn 2014). Radiometers equipped with frequency channels that are far from each other (e.g., $\mathrm{C}$ band and $\mathrm{X}$ to $\mathrm{Ku}$ band) are more complex. With significant differences in footprint dimensions and, consequently, different beam-filling effects, it is difficult to precisely separate the contributions from precipitation and atmospheric sources.

The Advanced Microwave Scanning Radiometer (AMSR and AMSR-E) sensor only operated a single $\sim 6.9-\mathrm{GHz}$ channel (V and $\mathrm{H}$ polarization) and had limited capacity in this respect. The follow-on,

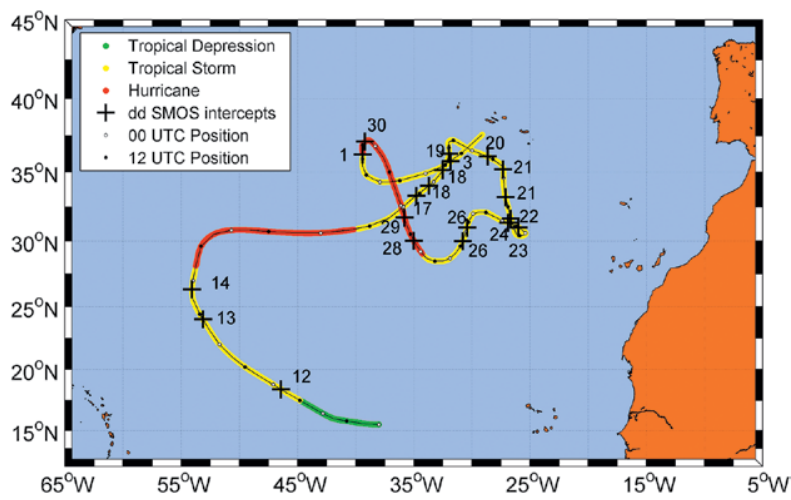

FIG. 2. Best track center position of Hurricane Nadine from 12 Sep to 4 Oct 2012. The black crosses indicate the location along the track at the time of 20 SMOS overpasses during the storm lifetime. Side numbers indicate the day of those overpasses.

AMSR-2, on board the Global Change Observation Mission-Water (GCOM-W) satellite launched in May of 2012, has two C-band channels at frequencies of 6.925 and $7.3 \mathrm{GHz}$ (Imaoka et al. 2010). This instrument features a $1,450-\mathrm{km}$-wide swath, an improved calibration with respect to AMSR-E, and a higher spatial resolution $(35 \mathrm{~km} \times 62 \mathrm{~km}$ for the C-band channels) due to larger antenna diameter. The addition of the two new C-band channels was initially intended for RFI identification, but they can be exploited to retrieve surface wind estimates. Signals at these two C-band frequencies have similar sensitivity to the sea wind speed but differ in sensitivity to rain by about $12 \%$. Note that the antenna patterns of both the 6.9- and 7.3-GHz channels have identical footprint sizes on Earth that overlap within $\sim 1-2 \mathrm{~km}$ [according to JAXA (2013)] so that wind and rain effects on both channels shall be comparable. An efficient multifrequency retrieval algorithm developed in a series of papers by Zabolotskikh et al. $(2013,2014,2015,2016)$ indeed demonstrates significant success when retrieving sea surface wind speed and rain in both tropical cyclones and polar lows. Accuracy of the AMSR-2-retrieved wind speed in storms is comparable to results obtained from SMOS and SMAP L-band sensors in the range 34-100 ktthat is, $\sim 10-12 \mathrm{kt}$ [see Zabolotskikh et al. (2014)].

\section{SPATIAL RESOLUTION: A LIMITATION TO INFERRING THE TC WIND INNER-CORE} REGION. SMOS, SMAP, and AMSR-2 all have relatively coarse spatial resolutions. The instantaneous field of view is about $40-50 \mathrm{~km}$, although gridded products of $15-25 \mathrm{~km}$ are routinely produced. As shown (Knaff et al. 2015), the climatological RMW 
in TCs is a function of both the storm center latitude and intensity. RMW decreases equatorward, reaching the smallest values in the tropics [less than $40 \mathrm{n} \mathrm{mi}$ $(\sim 80 \mathrm{~km})]$, but is also significantly smaller as storm intensity increases. The climatological RMW is thus $\sim 100 \mathrm{~km}$ at tropical storm force decreasing to $\sim 46 \mathrm{~km}$ when MSW reaches 100 kt [see Fig. 2 in Knaff et al. (2015)]. For MSW higher than this threshold wind speed (categories 3-5 on the Saffir-Simpson hurricane wind scale), the RMW exhibits average values below the spatial resolution of all SMOS, SMAP, or AMSR-2 instruments. In these conditions, the relatively poor spatial resolution of L-band and dual C-band orbiting radiometer data generally does not allow an accurate determination of the RMW, resulting in underestimated MSW above $100 \mathrm{kt}$ [see discussion in Reul et al. (2016) and Yueh et al. (2016)]. The brightness temperature observed in the TCs' inner-core region by radiometers with a $\sim 40-50-\mathrm{km}$ spatial footprint includes bright contributions from around the maximum wind region and significantly lower brightness power emitted from the very calm wind region in the eye. The spatial averaging of the antenna therefore results in significantly smoother high wind gradients retrieved from the satellite data than actually encountered in the proximity of the storm inner core.

In addition, 1-min maximum sustained winds as estimated from best track data cannot be expected to match the MSW extracted from instantaneous $40-\mathrm{km}$ spatial average satellite observations. These considerations make the MSW and RMW structural parameters estimated from instantaneous large-scale satellite footprint difficult variables to estimate and to calibrate. Yet, as found in Reul et al. $(2012,2016)$ and the examples we will show further, the outer wind structure including 34-, 50-, and 64-kt winds can nevertheless be correctly estimated from these sensors.

The "SMOS-STORM" and best track database. Surface wind products have been systematically generated for SMOS and SMAP sensors using the Reul et al. (2016) algorithm to cover all tropical cyclones intercepted by both instruments from mid-2010 to the end of 2015 . This database has been complemented by the wind field derived from AMSR-2 TC intercepts using the algorithm of Zabolotskikh et al. (2013, 2014, 2015, 2016) to cover all TCs worldwide during the period from mid2012 to the end of 2015. All SMOS, SMAP, and AMSR-2 wind data used in this study form the so-called SMOSSTORM project database and are freely available in netCDF format at www.smosstorm.org.

This study will concentrate on wind radii verification statistics based on the estimates contained in the automated tropical cyclone forecast (ATCF) best track files (Sampson and Schrader 2000). ATCF best track files (a.k.a. B decks) are available from NHC (http:// ftp.nhc.noaa.gov/atcf/) and provide official synoptic hour positions, intensity, and wind radii of tropical cyclones. To calculate verification statistics, best track values of storm center position and of the wind radii at $34 \mathrm{kt}$ (R34), $50 \mathrm{kt}$ (R50), and $64 \mathrm{kt}$ (R64) in each quadrant, all provided at synoptic hours, are linearly interpolated at each satellite swath/storm intercept time. The wind radii values are further estimated from the satellite microwave imagery based on the distance from the time-interpolated storm center location and the points belonging to the wind contour curves determined in each quadrant at 34,50 , and $64 \mathrm{kt}$. We found that the maximum distance of all wind contour points detected at a given wind speed in a given storm quadrant from the satellite imagery very often provides higher wind radii than the best track values. Further investigation revealed that these biases are predominantly associated with the presence of small distant patches of high wind speeds often detected in the satellite imagery (e.g., see further examples in Fig. 3). To systematically filter out these small high wind patches, we determined the wind radii from the satellite imagery using only the longest contour curve detected within each quadrant at fixed wind speed. A wind radii estimate from either SMOS, AMSR-2, or SMAP data was further considered valid only if more than $50 \%$ of the gridded satellite data are available within the satellite-determined radius for a given quadrant.

While best track data are verified postseason, we recognize that there is some debate about whether the wind radii in the best tracks can serve as ground truth for wind product evaluation because of concerns over sparse, intermittent, and poor quality observations used to estimate them. Accuracy of the wind radii in the best tracks is discussed in detail in Knaff and Harper (2010), Landsea and Franklin (2013), and Knaff and Sampson (2015). Best track wind radii are estimated to have errors as high as $10 \%-40 \%$, depending on the observation capabilities. Nevertheless, they are the "best estimates" available and are consistently generated to cover the period since the launch of SMOS (end of 2009).

Hurricane Nadine: An illustration of SMOS data capability to provide reliable estimates of gale-force $(34 \mathrm{kt})$ wind radii. Nadine was an unusually long-lived tropical cyclone that developed from 8 September to 4 October 2012 and completed three loops over the eastern subtropical Atlantic (see Fig. 2). Nadine attained 


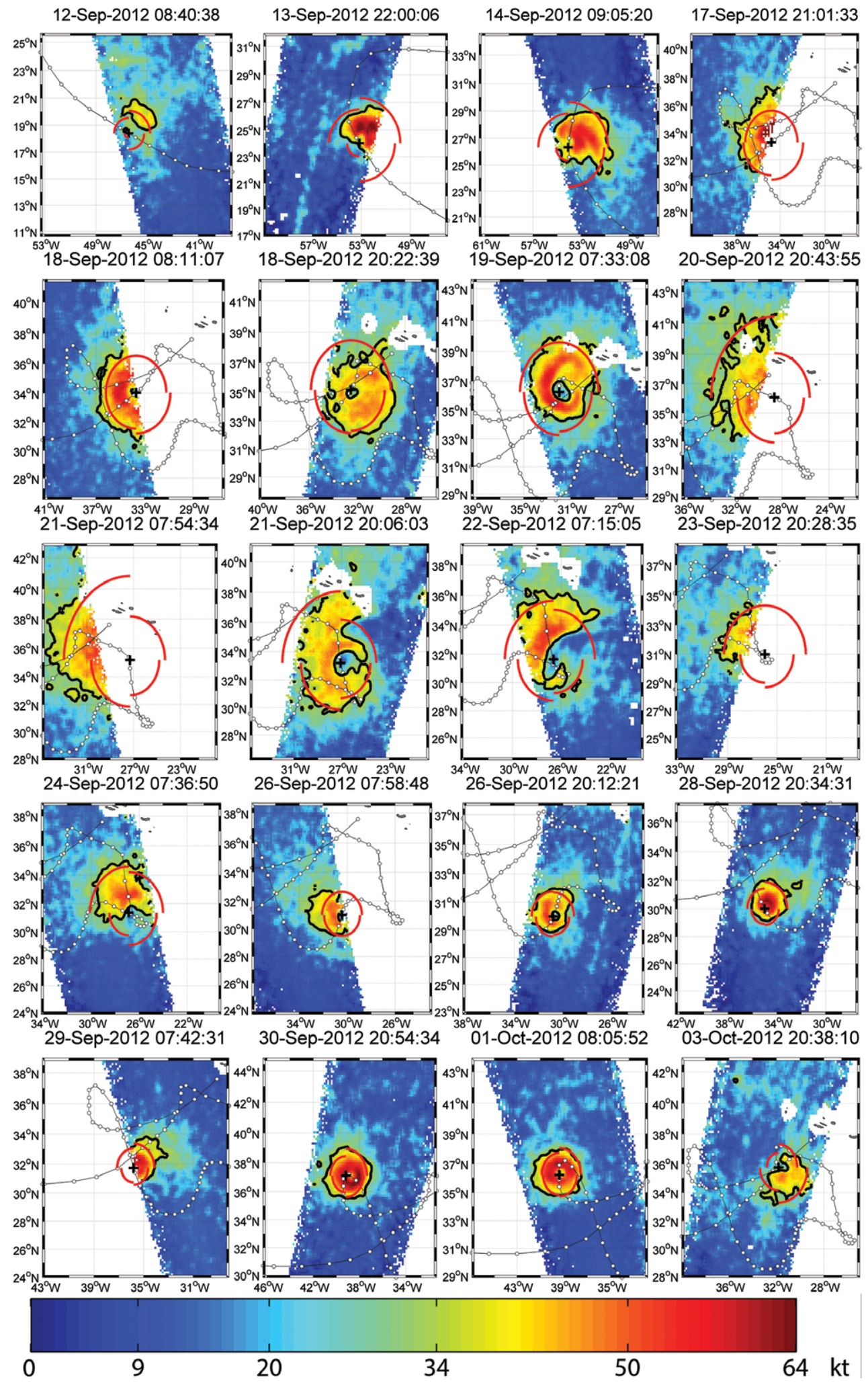

FIG. 3. Mosaic of 20 successive wind fields (color in kt) retrieved from SMOS data during the evolution of category I Hurricane Nadine in the North Atlantic from (top left) I 2 Sep to (bottom right) 3 Oct 2012. Nadine was the fourth longest-lived Atlantic hurricane on record. In each plot, the storm track is shown as a white dotted curve. The location of the storm center at the time of SMOS overpass is illustrated by a black cross. The thick black curve is showing the SMOS wind field contour at $34 \mathrm{kt}$. The red arcs are showing the ATCF b-deck gale-force ( $34 \mathrm{kt})$ wind radii. 
hurricane strength on two occasions (from 14 to 15 September and from 28 September to 2 October)a record 13 days apart. During its lifetime, the SMOS instrument performed a series of about 25 overpasses over the storm. Given the variability of the respective geometry of interception of the storm by the satellite swath, 20 of those overpasses were finally selected for analysis, presenting sufficient data coverage to infer gale wind radii in one, or several, storm quadrants at a given time. The useful satellite intercepts mostly cover the storm period after 17 September (Fig. 2). The wind fields successively estimated from SMOS data and the corresponding wind contours at $34 \mathrm{kt}$ (black curves) during the Nadine storm lifetime are shown in Fig. 3, together with the ATCF best track gale-force wind radii data (red arcs). As illustrated, although there are some local differences, the wind speed contours at $34 \mathrm{kt}$ in SMOS data generally well match (at least visually) the radial extent of gale winds estimated from the best track data and its variability all along the storm lifetime. The 6-hourly best track R34 data and SMOS 34-kt radii time series per quadrant shown in Fig. 4 further emphasize the capability of SMOS estimates to well reproduce the best track $34-k t$ wind radii data and their temporal variability as determined in each quadrant of the storm. While statistics shown further will confirm the facts, this example for Hurricane Nadine is illustrative of the potential of low-frequency microwave radiometers such as SMOS to provide useful gale-force wind radii information complementing existing radiometer (IR, MI) and scatterometer observations.

Wind radii estimated at 34, 50, and $64 \mathrm{kt}$ from SMOS and AMSR-2: Ensemble comparison with best track. More quantitative assessment of the relative quality of estimated wind radii from sensors such as SMOS with respect to the best track data are provided herein by comparing the radii at 34,50 , and $64 \mathrm{kt}$ between both datasets for an ensemble of about 200 TCs, each intercepted several times by SMOS's swath in the North Atlantic and east Pacific during the 2010-15 hurricane seasons. About 9,000, 4,000, and 1,200 matchup pairs of wind radii estimations at 34,50 , and $64 \mathrm{kt}$ were obtained, respectively, considering all storm quadrant estimates. Statistical analyses of the differences between SMOS and best track radii are shown in Fig. 5. As found, the radii retrieved from SMOS data at all three wind forces $(34,50$, and $64 \mathrm{kt})$ are unbiased with respect to best track data except for
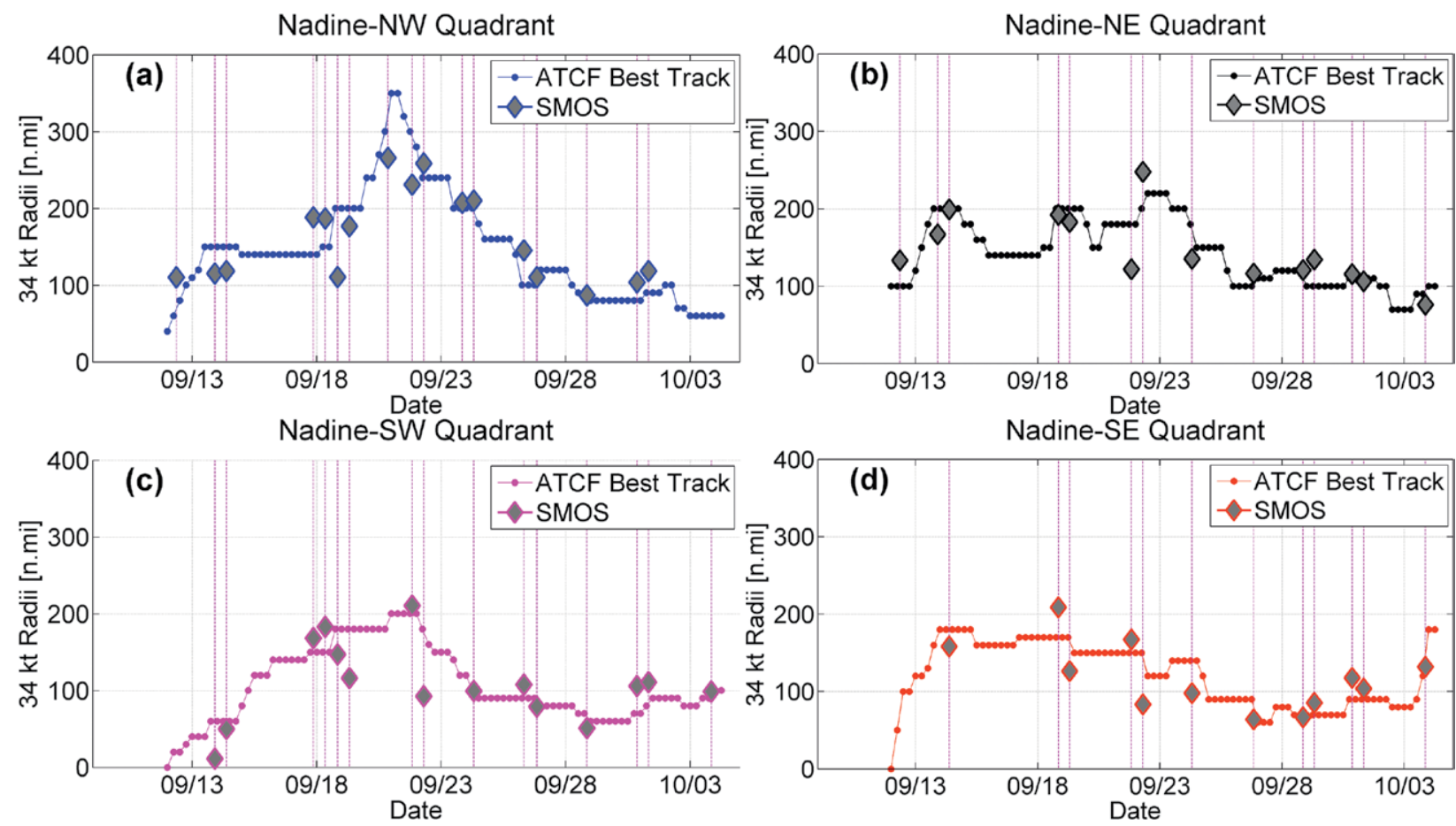

FIG. 4. Time series of the gale-force $(34 \mathrm{kt})$ wind radii from ATCF best track (dotted color curves) and from SMOS (diamonds) data in $\mathbf{n}$ mi during the evolution of Hurricane Nadine in the North Atlantic in 20I2. Galeforce wind radii are provided per compass quadrants surrounding the TC: (a) northwest quadrant, (b) northeast quadrant, (c) southwest quadrant, and (d) southeast quadrant. Vertical thin dotted lines indicate the times at which an SMOS intercept is available to provide one of the quadrant estimates. 
radii smaller than about $15-20 \mathrm{n} \mathrm{mi}$ and when they exceed $250 \mathrm{n} \mathrm{mi} \mathrm{(which} \mathrm{roughly} \mathrm{corresponds} \mathrm{to} \mathrm{half} \mathrm{the}$ SMOS swath width). For these large radii with respect to the instrument swath, which are mostly found in gale-force winds (Fig. 5a), the extent of the $34-\mathrm{kt}$ wind generally exceeded the size of the wind field imaged by the instrument, adding uncertainty to the retrievals.

The histograms of the differences $\Delta R_{\text {ATCF-SMOS }}$ are well approximated by Gaussian distributions for the three types of radii (Fig. 5, right column), with mean values below $4.5 \mathrm{n} \mathrm{mi}$ and standard deviation of 27 , 18 , and $15.5 \mathrm{n} \mathrm{mi}$ for $34-, 50-$, and $64-\mathrm{kt}$ wind radii, respectively. These values are well below the best track uncertainties from satellite-only measurements (i.e., no aircraft data) and regardless of storm intensity as reported in Landsea and Franklin (2013). These authors indeed estimated best track uncertainties in these conditions of $\sim 40,30$, and $24.5 \mathrm{n} \mathrm{mi}$ for the gale (34 kt), storm (50 kt), and hurricane (64 kt) radii, respectively. These analyses reveal that SMOS data consistently provide useful information on those three important wind radii characterizing the storm outer structures. The SMOS wind radii estimates are generally coherent with best track ones with relative uncertainties smaller than the average uncertainties of the best track data themselves for the North Atlantic and east Pacific TCs. Similar analyses shall be conducted in future works to assess the relative differences in wind radii for other tropical cyclone basins. It is expected that the quality of SMOS wind radii estimates will be degraded in the west Pacific and north Indian Ocean owing to significantly higher RFI contaminations in these zones.

Similar analyses have been conducted to assess the relative differences between best track and AMSR-2 estimates for the gale (34 kt), storm (50 kt),
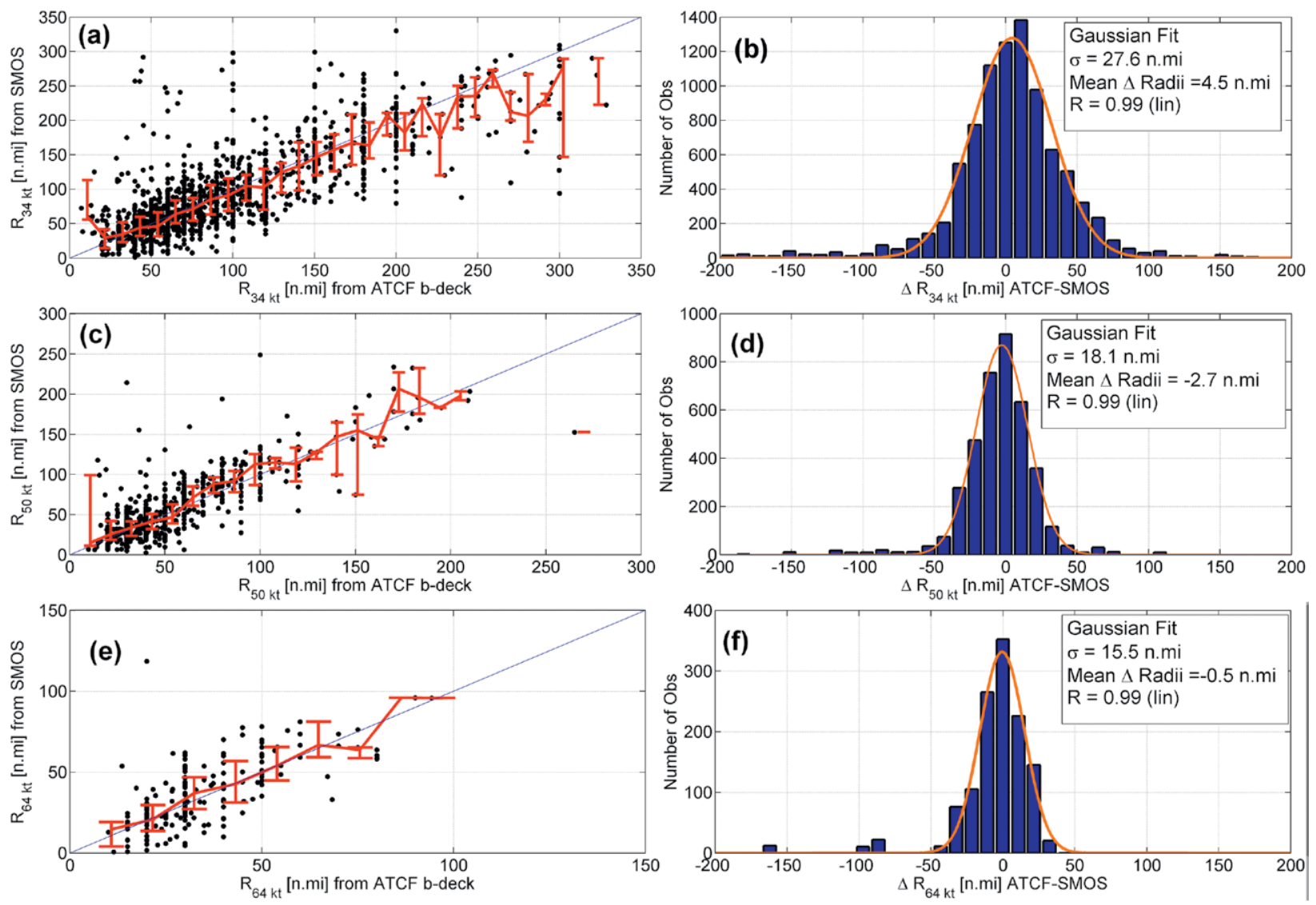

FIG. 5. Comparisons between SMOS-retrieved and ATCF b-deck wind radii estimates for an ensemble of satellite intercepts of 219 tropical cyclones in the North Atlantic and east Pacific between 2010 and 2015. Radii estimated from SMOS data ( $y$ axis) as a function of ATCF radii ( $x$ axis) are shown by black dots (n mi) for (a) 34-, (c) 50-, and (e) 64-kt wind radii. The thick red curve is showing the median of SMOS radii per bins of $10 \mathrm{n}$ mi of ATCF. The vertical bars indicate the extents of the $25 \%$ and $\mathbf{7 5} \%$ percentiles for each bin. Histograms of the differences $\Delta R$ between SMOS and ATCF wind radii (blue curve) and Gaussian function fits through the histograms (orange curve) are provided for (b) 34-, (d) 50-, and (f) 64-kt wind radii. The standard deviations of the Gaussian fits are 27, 18, and $15.5 \mathrm{n}$ mi for 34-, 50-, and 64-kt radii, respectively. 
and hurricane (64 kt) radii. The AMSR-2/ best track wind radii matchup database covers the same two TC basins from May 2012 to the end of 2015 and includes 4,200, 1,800, and 380 data pairs for 34-, 50-, and 64-kt wind radii, respectively. Results shown in Fig. 6 illustrate that AMSR-2 data also provide reliable information on all three radii. The histograms of the differences $\Delta R_{\text {ATCF-AMSR2 }}$ are also well approximated by Gaussian distributions for the three types of radii with mean values below $6 \mathrm{n} \mathrm{mi}$ and standard deviations of 26,15 , and $14.5 \mathrm{n} \mathrm{mi}$ for $34-, 50-$, and 64-kt wind radii, respectively. While more samples would be definitively required to ensure robustness of the statistical results, particularly at the highest 64-kt wind radii, the relative differences between AMSR-2 and best track radii are also well below the reported best track uncertainties from satellite-only measurements.

Multisensor wind field structure sensing over Hurricanes Jimena, Ignacio, and Kilo. The 2015 Pacific hurricane season was the second most active Pacific hurricane
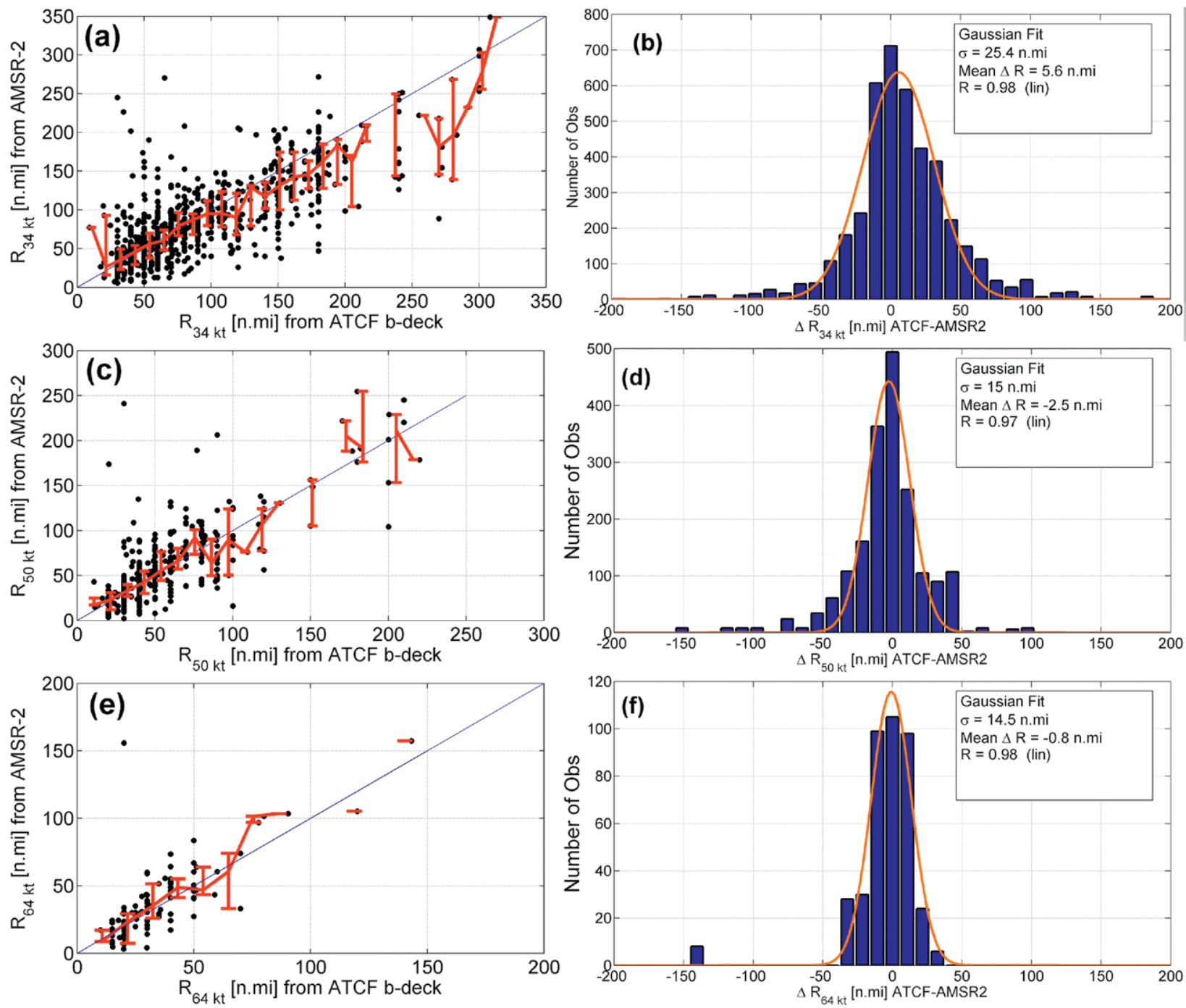

Fig. 6. Comparisons between AMSR-2-retrieved and ATCF b-deck wind radii estimates for an ensemble of satellite intercepts of 116 tropical cyclones in the North Atlantic and east Pacific between mid-20I2 and 2015. Radii estimated from AMSR-2 data $(y$ axis) as a function of ATCF radii ( $x$ axis) are shown by black dots $(\mathrm{n}$ mi) for (a) 34-, (c) 50-, and (e) 64-kt wind radii. The thick red curve is showing the median of SMOS radii per bins of $10 \mathrm{n} \mathrm{mi}$ of ATCF. The vertical bars indicate the extents of the $25 \%$ and $75 \%$ percentiles for each bin. Histograms of the differences $\triangle R$ between SMOS and ATCF wind radii (blue curve) and Gaussian function fits through the histograms (orange curve) are provided for (b) 34-, (d) 50-, and (f) 64-kt wind radii. The standard deviations of the Gaussian fits are 27,18 , and $15.5 \mathrm{n}$ mi for 34-, 50-, and 64-kt radii, respectively. 
season on record. It produced a record 31 tropical depressions, of which 26 became named storms, 16 became hurricanes, and a record 11 storms became major hurricanes throughout the season. Three of these major hurricanesnamely Jimena, Ignacio, and Kilo-developed in between 20 August and 10 September. Figure 7a shows a visible image composite obtained from NASA's Terra satellite revealing three simultaneous category 4 hurricanes east of the international date line on 29-30 August, the first such occurrence in recorded history. Figure $7 \mathrm{~b}$ shows retrieved surface wind speed fields of each hurricane measured independently within the swath of SMOS, SMAP, and AMSR-2 missions as they intercepted the three hurricanes on 29-30 August. These instruments regularly intercepted the three hurricanes during their lifetimes and from 21 August to 9 September, collectively imaged the hurricanes 96 times all along their evolution (see Fig. 8). An overview of the three storms synoptic history is first provided below.

Jimena. Tropical depression Thirteen-E located southwest of the coast of Mexico became Tropical Storm Jimena on 27 August and rapidly strengthened into a category 1 hurricane on 28 August. It was upgraded to a category 4 major hurricane the next day and reached its peak intensity with winds of $134 \mathrm{kt}$. On 29 August, Jimena underwent an eyewall replacement cycle, prompting weakening. Jimena completed the cycle on the next day and started to restrengthen. The restrengthening brought Jimena back to winds of $130 \mathrm{kt}$, before weakening again as it turned northwest. Early on 10 September, Jimena finally degenerated to a posttropical remnant low.

IGNACIO. On 25 August, a low pressure system formed and organized into tropical depression Twelve-E around $\left(12^{\circ} \mathrm{N}, 120^{\circ} \mathrm{E}\right)$, before strengthening into Tropical Storm Ignacio and heading westward. On 26 August, Ignacio became a category 1 hurricane, while continuing its trek toward Hawaii and was able to quickly intensify to major hurricane status on 29 August, attaining winds of $100 \mathrm{kt}$. Ignacio continued to rapidly intensify, attaining peak intensity at category 4 status with winds of $126 \mathrm{kt}$ on 30 August. After peaking in intensity, Ignacio began weakening after moving into a less favorable environment. The storm weakened to tropical storm strength on 1 September but was able to retain hurricane status. This would repeat once again, before the storm weakened to a tropical storm for the last time, and became posttropical $6 \mathrm{~h}$ later, while heading north.

KILO. On 20 August, a third low pressure area south of Hawaii strengthened into Tropical Storm Kilo and continued strengthening until it weakened into a tropical depression on 23 August. The storm 
would remain at tropical depression strength for the next three days. On 26 August, Kilo was able to restrengthen into a tropical storm. Intensification resumed the next day, with Kilo reaching hurricane strength. By 29 August, Kilo had rapidly intensified into a major hurricane, as the storm neared the international date line. Kilo peaked in intensity on 30 August as a category 4 hurricane with winds of $120 \mathrm{kt}$. After peaking in strength, Kilo fluctuated between category 3 and 4 strength as it slowly moved northwest, before slowly weakening below major hurricane status as conditions became less favorable. It crossed the date line early on 1 September, becoming Typhoon Kilo. Hurricane/Typhoon Kilo continued on to become one of the longest-lived tropical cyclones on record, with a total lifespan of 22 days-just over 3 weeks.
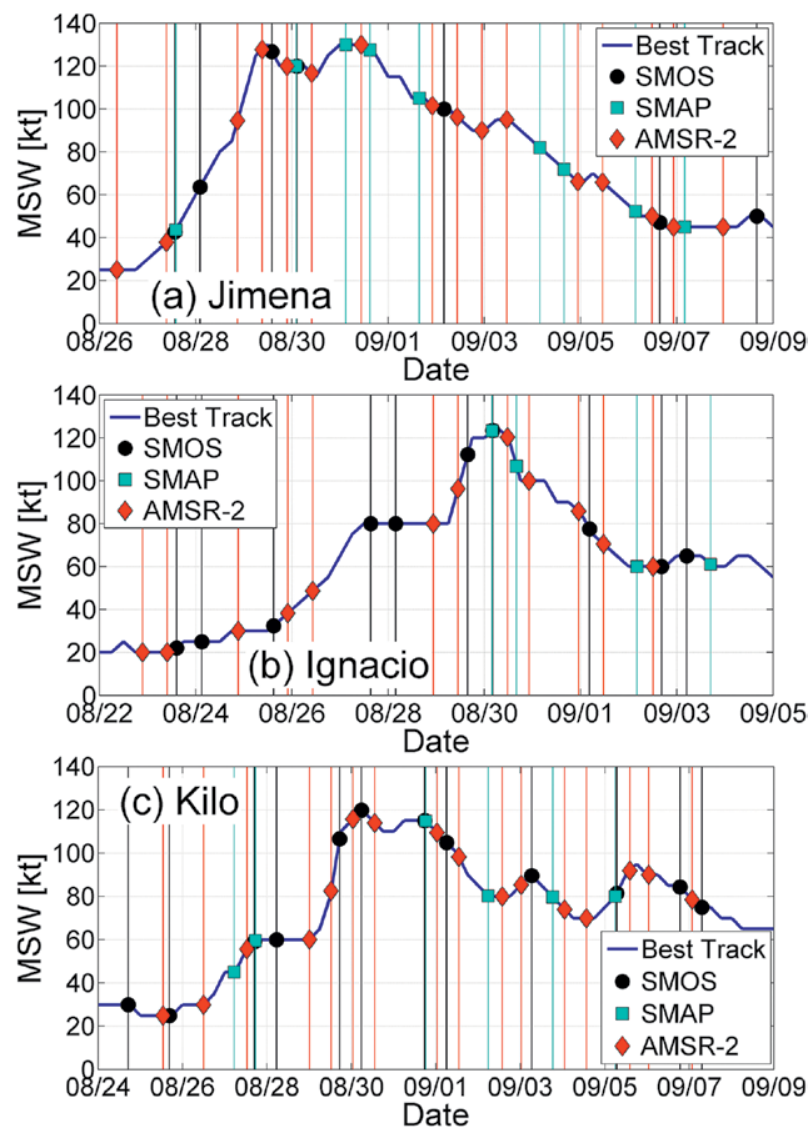

FIG. 8. Time series of the best track maximum sustained wind (kt) (blue curves) for Hurricanes (a) Jimena, (b) Ignacio, and (c) Kilo, which developed from 22 Aug to 9 Sep 2015. The storm intensity at the times (vertical bars) at which the three satellite swaths intercepted the storms are also indicated for SMOS (black filled circles), for SMAP (cyan filled circles), and for AMSR-2 (red diamonds) sensors.
SMOS, SMAP, and AMSR-2 wind radii versus best track. From the ensemble of 96 SMOS, SMAP, and AMSR-2 wind speed snapshots, we systematically determined the 34-, 50-, and 64-kt wind radii for each quadrant along each storm intercept, when sufficient data were available. The spatial and temporal distributions of wind radii estimated for each hurricane at 34,50 , and $64 \mathrm{kt}$ from both the best track and the merged SMOS/ SMAP/AMSR-2 dataset are successively illustrated in Figs. 9-12. In general, the structural evolution of the Jimena, Ignacio, and Kilo storms is in very good agreement between both data types for most of the storm lifetimes, although some local differences can be clearly detected.

The distribution of the overall differences between the best track and the SMOS/SMAP/AMSR-2 dataset for R34, R50, and R64 estimates for the three hurricanes is again found to be approximately Gaussian (see Fig. 13) with standard deviation of $23,15.5$, and $15.4 \mathrm{n} \mathrm{mi}$, respectively. These numbers are similar to the results reported previously from SMOS or AMSR-2 alone based on a much larger number of TC cases (see Figs. 5 and 6).

R50 results from the SMOS/SMAP/AMSR-2 dataset nevertheless often show departure from the best track in most quadrants during the end decaying phase of the hurricanes. Significant biases are particularly evident for the cases of Jimena (see Fig. 10, middle column) and Kilo (see Fig. 12, middle column) in these periods. R50 from the best track for the case of Jimena thus clearly decreases in all quadrants shortly after 5 September while the merged low-MW satellite dataset shows a nondecreasing and significantly larger R50 than the best track (by 40-60 n mi). Similarly, R50 estimated from SMOS/SMAP/AMSR-2 dataset systematically overestimates the best track data after 5 September for the case of Hurricane Kilo.

The merged satellite R64 dataset seems also to slightly overestimate the best track data in general by $\sim 10 \mathrm{n} \mathrm{mi}$, with, as for R50, larger biases during the end decaying periods of the three TCs. It is well known (Young 2003; Young and Vinoth 2013) that large amplification of the wave energy often occurs in the right-front storm quadrant. A wave-enhancement criterion can be derived (Kudryavtsev et al. 2015). The resulting significant wave height does not strongly depend on wind speed but, comparatively, more on the storm translation velocity, particularly in the TC decay phase. Differences in the wave and wind field asymmetries around the storm track could displace the brightest microwave temperature from the maximum wind 
area toward the maximum of surface foam production. These maxima might not systematically coincide, particularly during the decay phases of TCs. Not accounting for sea state impact on the brightness temperature can thus generate shifts in the storm apparent wind structure: this may explain the discrepancies between SMOS/SMAP/ AMSR-2 and IR data estimates of the most intense wind radii in the decaying phases.

SUMMARY. The production of quality wind radii in tropical cyclones is important to operations as they provide quantitative estimates of the TC wind structure for the production of effective warnings of on-station and on-ship gale-force (34 kt), damaging (50 kt), and destructive $(64 \mathrm{kt})$ winds. Wind radii provide initial conditions for a number of applications such as wind speed

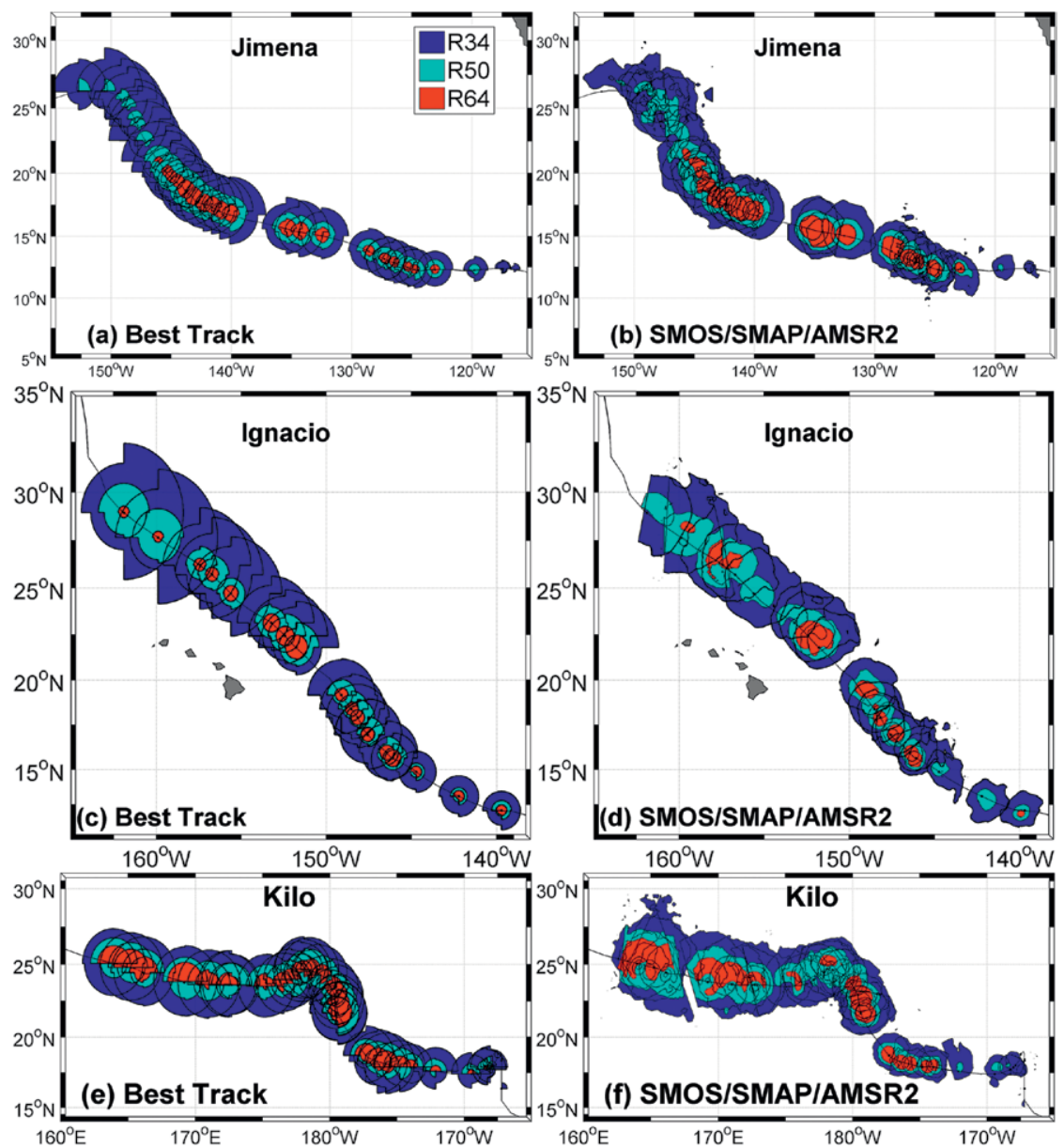

FIG. 9. Wind radii estimates from (left) the best track and from (right) the merged SMOS/SMAPIAMSR-2 surface wind dataset retrieved along the tracks of Hurricanes (a),(b) Jimena; (c),(d) Ignacio; and (e),(f) Kilo. All wind radii estimates are shown at every satellite intercepts time with 34-, 50-, and 64-kt wind radii being displayed in blue, cyan, and red, respectively. probabilities (DeMaria et al.

2013), TC conditions of readiness (Sampson et al. 2012), and wave forecasting (Sampson et al. 2010) and also for numerical models (Bender et al. 2007; Tallapragada et al. 2014). Specifying the correct initial TC surface wind structure also appears to improve hurricane model track and intensity performance (Bender et al. 2015). In addition, the extent of the primary vortex has been shown to be important for vortex resiliency (Reasor et al. 2004), the evolution of the inner-core structure (Xu and Wang 2010), the response of winds to convective heating (Musgrave et al. 2012), the potential for secondary eyewall formation (Rozoff et al. 2012), future intensification rates (Xu and Wang 2015), etc. Asymmetries in wind radii are important to operations as they affect the distribution of high seas associated with TCs (Lazarus et al. 2013; Sampson et al. 2010), storm surge and inundation (Probst and Franchello 2012), and other risks.
While advances in our understanding of the physics underpinning the life cycle of tropical storms and their development into hurricanes is advancing all the time, there is no substitute for improved measurement capability that can help define the character of a given storm. This is particularly important for satellite measurements that are obtained from a variety of instruments operating at different frequencies with different capabilities. The relatively new L-band and dual-channel C-band passive measurements that we report here are a welcome addition to the existing armory of measurements used by the operational hurricane forecasting centers around the world. As with all measurements, they are not perfect, but the wide-swath regular repeat coverage and ability to provide measurements of surface wind speed structure at hurricane force in the presence of heavy precipitation is unique. Verification data show that the new generation of 
satellite microwave instruments are useful to provide radii at 34,50, and $64 \mathrm{kt}$ alongside ASCAT and WindSat. Furthermore, each of these measurement classes offers a complementary measurement-with the current generation of scatterometer and radars providing high-quality, higher-spatial-resolution wind vector estimates but potentially affected by heavy rain in TCs at Ku band (Weissman et al. 2002), but also at $\mathrm{C}$ band (Katsaros et al. 2002; Chou et al. 2013), and by the reduced sensitivity of the dualpolarization normalized radar cross section (both at $\mathrm{Ku}$ and $\mathrm{C}$ bands) in the highest wind speed domains of the TCs (Donnelly et al. 1999; Fernandez et al. 2006; Chou et al. 2013). The L- and dual C-band passive sensors presented here are limited by their coarse spatial resolution but, in general, they do provide meaningful information on the wind radii of gale (34 kt), storm (50 kt), and hurricane (64 kt) force winds. In general, we found that the differences between the parameters estimated from SMOS, SMAP, and AMSR-2 data and the best track data are smaller than the uncertainties in the best track wind radii data themselves. Discrepancies between SMOS/SMAP/AMSR-2 and IR data estimates of the most intense wind radii were nevertheless detected during the decay phases of TCs. Further research will be needed to separate the wind and sea state effects on the brightness temperature and to refine the estimation of 50- and 64-kt wind radii in situations of decaying TC intensity.

The ESA SMOS+ STORM project (see www .smosstorm.org) database of multiple-sensor satellite data corresponding to TC and extra-TC conditions across the global oceans will be continually updated with new measurements and provides an easy to use dataset for those wishing to explore their application. Finally, ESA is now developing a near-real-time product for SMOS (within 3-6 h from acquisition) for trial applications in operational forecasting centers. We plan to include production of wind radii fixes from these data and look forward to an exciting era of new developments in TC analysis and forecasting using the new generation of satellite instruments available today.
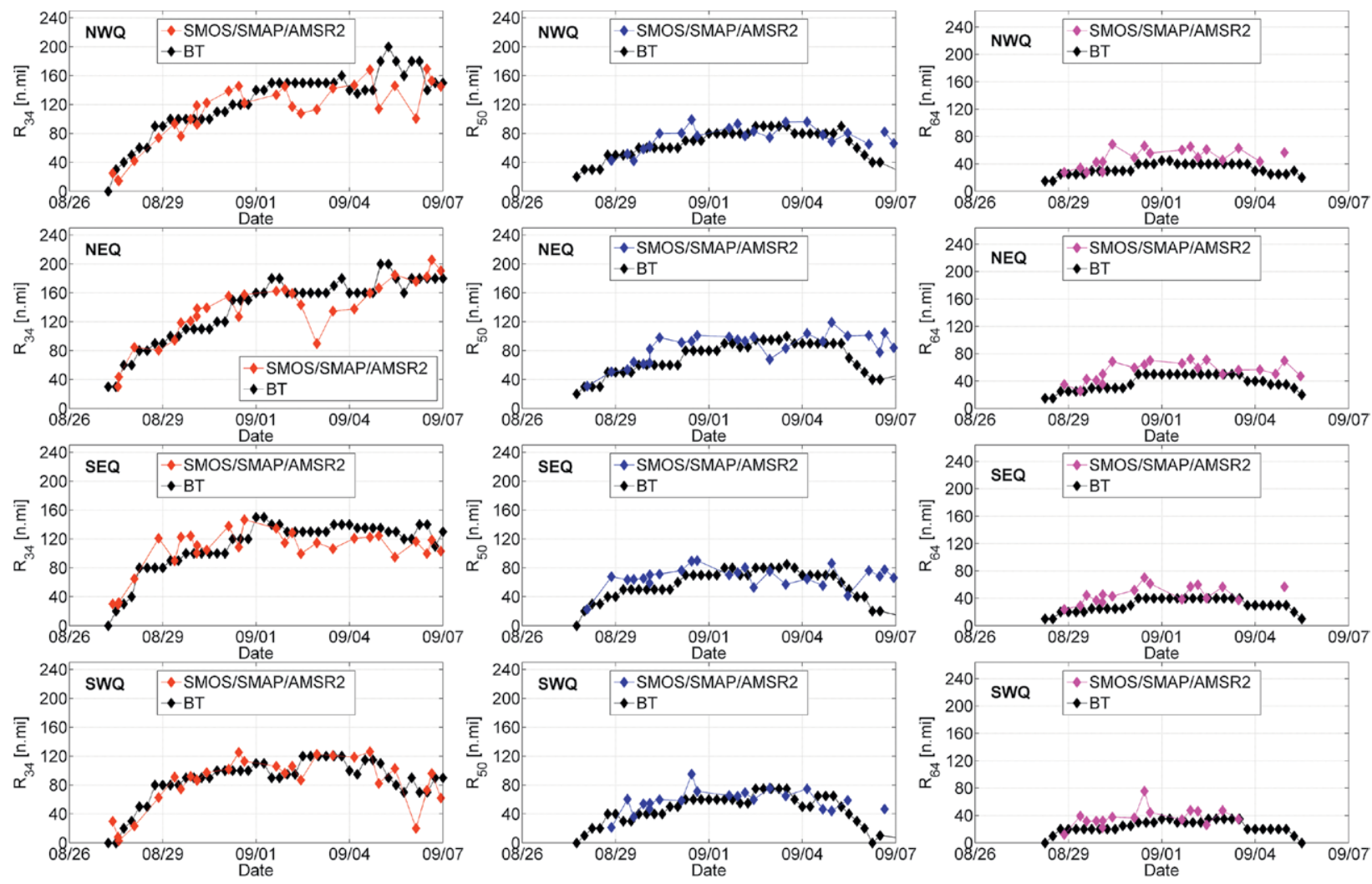

FIG. 10. Time series of (left) gale-force wind radii (34 kt), (middle) damaging-force wind radii (50 kt), and (right) hurricane-force wind radii $(64 \mathrm{kt})$ estimates from the best track (black diamonds) and from the merged SMOS/SMAPIAMSR-2 surface wind speed dataset (red, blue, and magenta diamonds for 34-, 50-, and 64-kt radii, respectively) retrieved along the tracks of Hurricane Jimena for the (from top to bottom) northwest quadrant, northeast quadrant, southeast quadrant, and southwest quadrant. 

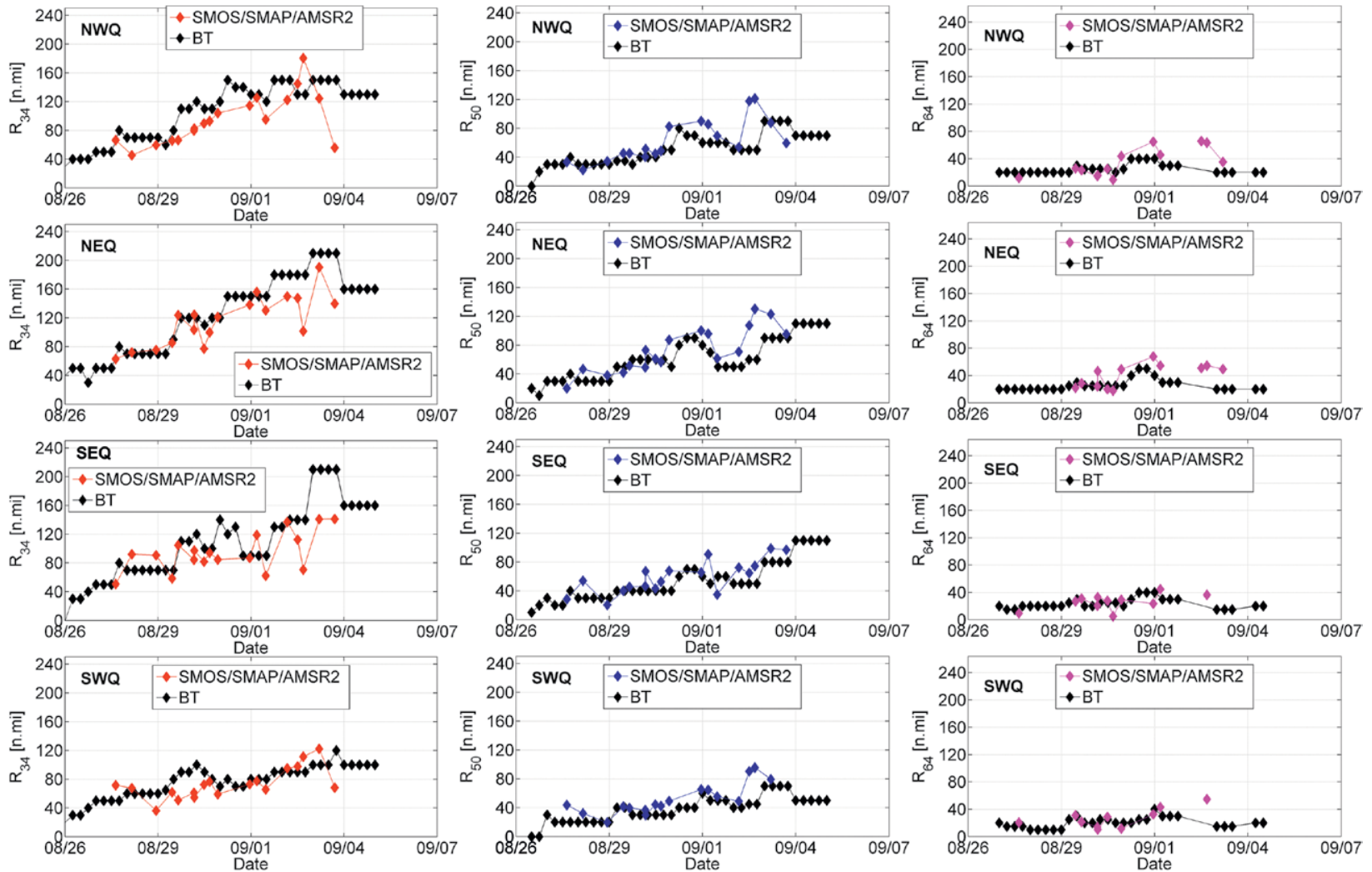

Fig. II. As in Fig. 10, but for Hurricane Ignacio.
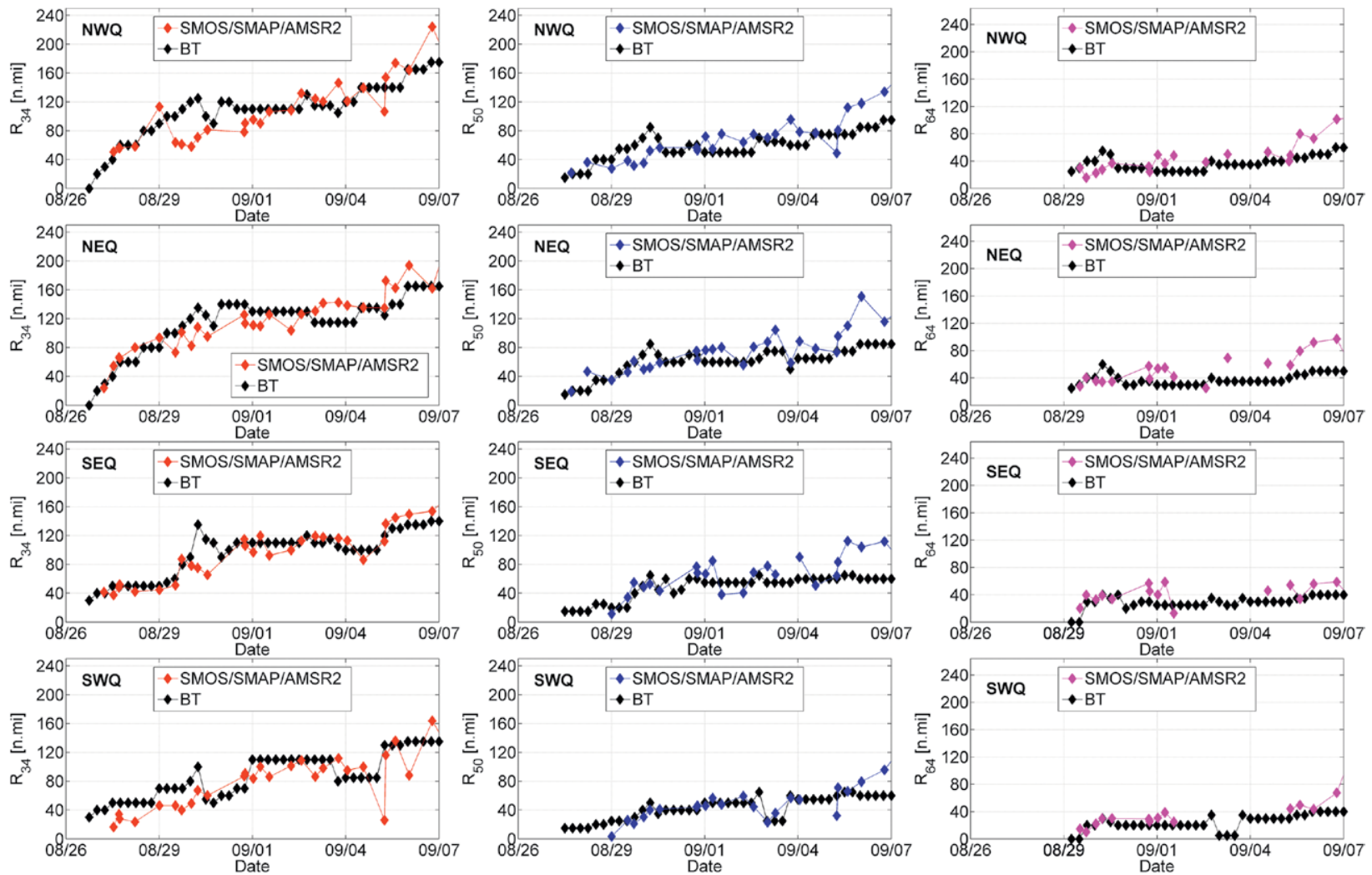

Fig. 12. As in Fig. 10, but for Hurricane Kilo. 

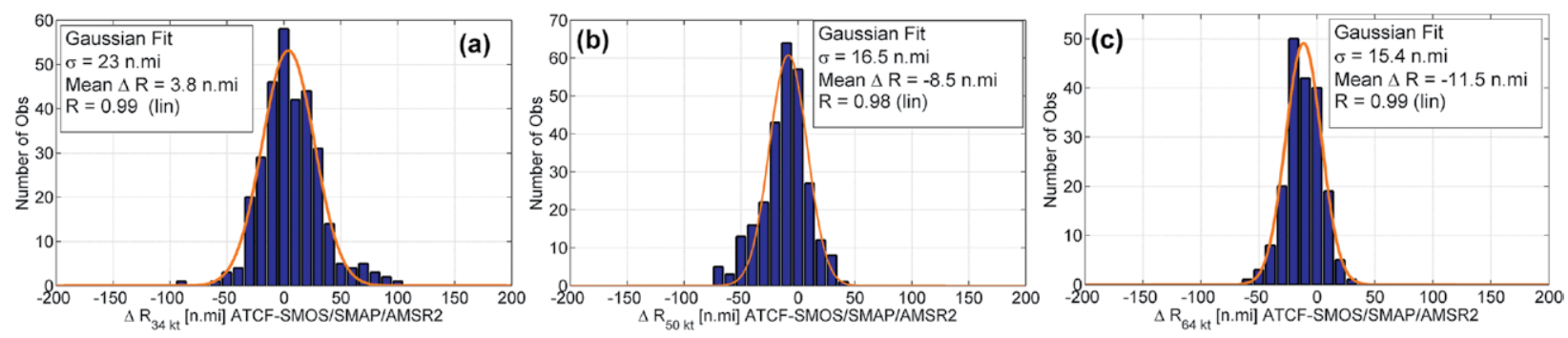

FIG. I3. Histograms of the differences $\Delta R$ between best track wind radii estimates and merged SMOS/AMSR-2I SMAP wind radii estimates at (a) 34 , (b) 50 , and (c) $64 \mathrm{kt}$ for the combined cases of Hurricanes Jimena, Ignacio, and Kilo that developed simultaneously in the Pacific in between 26 Aug and 9 Sep 2015.

ACKNOWLEDGMENTS. The work described in this paper was carried out by IFREMER, OceanDatalab, and the Met Office under the European Space Agency SMOS + STORM Evolution Contract 4000105171/12/I-BG under its Support to Science Element (STSE) program. The specific work described in this paper that was carried out by the Jet Propulsion Laboratory, California Institute of Technology was performed under a contract with the National Aeronautics and Space Administration. RSHU was funded by the Ministry of Education and Science of the Russian Federation through the Project RFMEFI58615X0017.

\section{REFERENCES}

Anguelova, M. D., and P. W. Gaiser, 2012: Dielectric and radiative properties of sea foam at microwave frequencies: Conceptual understanding of foam emissivity. Remote Sens., 4, 1162-1189, doi:10.3390 /rs4051162.

Bender, M. A., I. Ginis, R. Tuleya, B. Thomas, and T. Marchok, 2007: The operational GFDL coupled hurricane-ocean prediction system and summary of its performance. Mon. Wea. Rev., 135, 3965-3989, doi:10.1175/2007MWR2032.1.

Bender, M. A., M. Morin, T. Marchok, I. Ginis, B. Thomas, and R. E. Tuleya, 2015: Upgrades to the GFDL/GFDN Operational Hurricane Models Planned for 2015. 69th Interdepartmental Hurricane Conf., Jacksonville, FL, Office of the Federal Coordinator for Meteorological Services and Supporting Research, S3b-01. [Available online at www .ofcm.gov/ihc15/presentations/Session3b/S3b-01 -Mbender2015IHC.Tuesday.pptx.]

Bettenhausen, M. H., C. K. Smith, R. M. Bevilacqua, N. Wang, P. W. Gaiser, and S. Cox, 2006: A nonlinear optimization algorithm for WindSat wind vector retrievals. IEEE Trans. Geosci. Remote Sens., 44, 597-610, doi:10.1109/TGRS.2005.862504.

Brennan, M. J., C. C. Hennon, and R. D. Knabb, 2009: The operational use of QuikSCAT ocean surface vector winds at the National Hurricane Center. Wea. Forecasting, 24, 621-645, doi:10.1175/2008WAF2222188.1.

Camps, A., and Coauthors, 2005: The emissivity of foam-covered water surface at L-band: Theoretical modeling and experimental results from the FROG 2003 field experiment. IEEE Trans. Geosci. Remote Sens., 43, 925-937, doi:10.1109/TGRS.2004.839651.

Chou, K.-H., C.-C. Wu, and S.-Z. Lin, 2013: Assessment of the ASCAT wind error characteristics by global dropwindsonde observations. J. Geophys. Res. Atmos., 118, 9011-9021, doi:10.1002/jgrd.50724.

DeMaria, M., and Coauthors, 2013: Improvements to the operational tropical cyclone wind speed probability model. Wea. Forecasting, 28, 586-602, doi:10.1175 /WAF-D-12-00116.1.

Demuth, J., M. DeMaria, J. A. Knaff, and T. H. Vonder Haar, 2004: Validation of an Advanced Microwave Sounder Unit (AMSU) tropical cyclone intensity and size estimation algorithm. J. Appl. Meteor. Climatol., 43, 282-296, doi:10.1175/1520-0450 (2004)043<0282:EOAMSU>2.0.CO;2.

— _ _ and — 2006: Improvement of Advanced Microwave Sounding Unit tropical cyclone intensity and size estimation algorithms. J. Appl. Meteor. Climatol., 45, 1573-1581, doi:10.1175/JAM2429.1.

Donnelly, W. J., J. R. Carswell, R. E. McIntosh, P. S. Chang, J. Wilkerson, F. Marks, and P. G. Black, 1999: Revised ocean backscatter models at $\mathrm{C}$ and Ku band under high-wind conditions. J. Geophys. Res., 104, 11 485-11 497, doi:10.1029/1998JC900030.

Dvorak, V. F., 1975: Tropical cyclone intensity analysis and forecasting from satellite imagery. Mon. Wea. Rev., 103, 420-430, doi:10.1175/1520 $-0493(1975) 103<0420$ :TCIAAF $>2.0$. CO;2.

El-Nimri, S. F., W. Lindwood Jones, E. Uhlhorn, C. Ruf, J. Johnson, and P. Black, 2010: An improved C-band ocean surface emissivity model at hurricane-force wind speeds over a wide range of Earth incidence angles. IEEE Geosci. Remote Sens. Lett., 7, 641-645, doi:10.1109/LGRS.2010.2043814. 
Entekhabi, D., and Coauthors, 2014: SMAP handbook. Jet Propulsion Laboratory Publ. JPL 400-1567, 182 pp. [Available online at https://smap.jpl.nasa.gov/system /internal_resources/details/original/178_SMAP _Handbook_FINAL_1_JULY_2014_Web.pdf.]

Fernandez, D. E., J. R. Carswell, S. Frasier, P. S. Chang, P. G. Black, and F. D. Marks, 2006: Dual-polarized $\mathrm{C}$ - and Ku-band ocean backscatter response to hurricane-force winds. J. Geophys. Res., 111, C08013, doi:10.1029/2005JC003048.

Hanafin, J. A., and Coauthors, 2012: Phenomenal sea states and swell from a North Atlantic storm in February 2011: A comprehensive analysis. Bull. Amer. Meteor. Soc., 93, 1825-1832, doi:10.1175/BAMS-D -11-00128.1.

Harrington, R. F., 1980: The development of a stepped frequency microwave radiometer and its application to remote sensing of the Earth. NASA Tech. Rep. NASA-TM-81847, 169 pp. [Available online at https://ntrs.nasa.gov/archive/nasa/casi.ntrs.nasa .gov/19800020136.pdf.]

Holmlund, K., C. Velden, and M. Rohn, 2001: Enhanced automated quality control applied to high-density satellite-derived winds. Mon. Wea. Rev., 129, 517529, doi:10.1175/1520-0493(2001)129<0517:EAQCAT $>2.0 . \mathrm{CO} ; 2$.

Holthuijsen, L. H., M. D. Powell, and J. D. Pietrzak, 2012: Wind and waves in extreme hurricanes. J. Geophys. Res., 117, C09003, doi:10.1029/2012JC007983.

Imaoka, K., and Coauthors, 2010: Global Change Observation Mission (GCOM) for monitoring carbon, water cycles, and climate change. Proc. IEEE, 98, 717-734, doi:10.1109/JPROC.2009.2036869.

Jarvinen, B. R., C. J. Neumann, and M. A. S. Davis, 1984: A tropical cyclone data tape for the North Atlantic Basin, 1886-1983: Contents, limitations and uses. NOAA Tech. Memo. NWS NHC 22, 21 pp. [Available online at www.nhc.noaa.gov/pdf /NWS-NHC-1988-22.pdf.]

JAXA, 2013: Data users' manual for the Advanced Microwave Scanning Radiometer 2 (AMSR2) onboard the Global Change Observation Mission 1st - Water "SHIZUKU" (GCOM-W1), 2nd edition. Japan Aerospace Exploration Agency, Earth Observation Research Center, 256 pp. [Available online at http://suzaku.eorc.jaxa.jp/GCOM_W/data/doc /amsr2_data_user_guide.pdf.]

Jourdain, N., M. Lengaigne, J. Vialard, G. Madec, C. Menkes, E. Vincent, S. Jullien, and B. Barnier, 2013: Observation-based estimates of surface cooling inhibition by heavy rainfall under tropical cyclones. J. Phys. Oceanogr., 43, 205-221, doi:10.1175/JPO -D-12-085.1.
Katsaros, K. B., P. W. Vachon, W. T. Liu, and G. P. Black, 2002: Microwave remote sensing of tropical cyclones from space. J. Oceanogr., 58, 137-151, doi:10.1023/A:1015884903180.

Kerr, Y. H., and Coauthors, 2010: The SMOS mission: New tool for monitoring key elements of the global water cycle. Proc. IEEE, 98, 666-687, doi:10.1109 /JPROC.2010.2043032.

Kidder, S. Q., W. M. Gray, and T. H. Vonder Haar, 1978: Estimating tropical cyclone central pressure and outer winds from satellite microwave data. Mon. Wea. Rev., 106, 1458-1464, doi:10.1175/1520 -0493(1978)106<1458:ETCCPA>2.0.CO;2.

Klotz, B. W., and E. W. Uhlhorn, 2014: Improved stepped frequency microwave radiometer tropical cyclone surface winds in heavy precipitation. $J$. Atmos. Oceanic Technol., 31, 2392-2408, doi:10.1175 /JTECH-D-14-00028.1.

Knaff, J. A., and B. A. Harper, 2010: Tropical cyclone surface wind structure and wind-pressure relationships. Proc. Int. Workshop on Tropical Cyclones VII, La Reunion, France, WMO, 35 pp. [Available online at www.wmo.int/pages/prog /arep/wwrp/tmr/otherfileformats/documents /Keynote1_JKnaffnBHarper.pdf.]

—, and C. R. Sampson, 2015: After a decade are Atlantic tropical cyclone gale force wind radii forecasts now skillful? Wea. Forecasting, 30, 702-709, doi:10.1175/WAF-D-14-00149.1.

—, S. P. Longmore, R. T. DeMaria, and D. A. Molenar, 2015: Improved tropical-cyclone flight-level wind estimates using routine infrared satellite reconnaissance. J. Appl. Meteor. Climatol., 54, 463-478, doi:10.1175/JAMC-D-14-0112.1.

—, C. J. Slocum, K. D. Musgrave, C. R. Sampson, and B. R. Strahl, 2016: Using routinely available information to estimate tropical cyclone wind structure. Mon. Wea. Rev., 144, 1233-1247, doi:10.1175/MWR-D-15-0267.1. Kossin, J. P., J. A. Knaff, H. I. Berger, D. C. Herndon, T. A. Cram, C. S. Velden, R. J. Murnane, and J. D. Hawkins, 2007: Estimating hurricane wind structure in the absence of aircraft reconnaissance. Wea. Forecasting, 22, 89-101, doi:10.1175/WAF985.1.

Kudryavtsev, V., P. Golubkin, and B. Chapron, 2015: A simplified wave enhancement criterion for moving extreme events. J. Geophys. Res. Oceans, 120, 75387558, doi:10.1002/2015JC011284.

Landsea, C. W., and J. L. Franklin, 2013: Atlantic hurricane database uncertainty and presentation of a new database format. Mon. Wea. Rev., 141, 3576-3592, doi:10.1175/MWR-D-12-00254.1.

Lazarus, S. M., S. T. Wilson, M. E. Splitt, and G. A. Zarillo, 2013: Evaluation of a wind wave system for 
ensemble tropical cyclone wave forecasting. Part I: Winds. Wea. Forecasting, 28, 297-315, doi:10.1175 /WAF-D-12-00054.1.

Mai, M., B. Zhang, X. F. Li, P. A. Hwang, and J. A. Zhang, 2016: Application of AMSR-E and AMSR2 lowfrequency channel brightness temperature data for hurricane wind retrievals. IEEE Trans. Geosci. Remote Sens., 54, 4501-4512, doi:10.1109/TGRS.2016.2543502.

Mecklenburg, S., and Coauthors, 2016: ESA's Soil Moisture and Ocean Salinity mission: From science to operational applications. Remote Sens. Environ., 180, 3-18, doi:10.1016/j.rse.2015.12.025.

Meissner, T., and F. J. Wentz, 2009: Wind vector retrievals under rain with passive satellite microwave radiometers. IEEE Trans. Geosci. Remote Sens., 47, 3065-3083, doi:10.1109/TGRS.2009.2027012.

Mueller, K. J., M. DeMaria, J. A. Knaff, J. P. Kossin, and T. H. Vonder Haar, 2006: Objective estimation of tropical cyclone wind structure from infrared satellite data. Wea. Forecasting, 21, 990-1005, doi:10.1175 /WAF955.1.

Musgrave, K. D., R. K. Taft, J. L. Vigh, B. D. McNoldy, and W. H. Schubert, 2012: Time evolution of the intensity and size of tropical cyclones. J. Adv. Model. Earth Syst., 4, M08001, doi:10.1029/2011MS000104.

Nordberg, W., J. Conaway, D. B. Ross, and T. Wilheit, 1971: Measurements of microwave emission from a foamcovered, wind-driven sea. J. Atmos. Sci., 28, 429-435, doi:10.1175/1520-0469(1971)028<0429:MOMEFA $>2.0 . \mathrm{CO} ; 2$.

Oliva, R., and Coauthors, 2016: Status of Radio Frequency Interference (RFI) in the $1400-1427 \mathrm{MHz}$ passive band based on six years of SMOS mission. Remote Sens. Environ., 180, 64-75, doi:10.1016/j .rse.2016.01.013.

Powell, M. D., S. H. Houston, L. R. Amat, and N. MorisseauLeroy, 1998: The HRD real-time hurricane wind analysis system. J. Wind Eng. Indust. Aerodyn., 77-78, 53-64.

Price, J. F., 1981: Upper ocean response to a hurricane. J. Phys. Oceanogr., 11, 153-175.

Probst, P., and G. Franchello, 2012: Global storm surge forecast and inundation modeling. JRC Scientific and Tech. Rep. EUR 25233 EN-2012, 47 pp. [Available online at http://portal.gdacs.org/about/Publications /ItemID/209/ModID/662.]

Quilfen, Y., B. Chapron, T. Elfouhaily, K. Katsaros, and J. Tournadre, 1998: Observation of tropical cyclones by high-resolution scatterometry. J. Geophys. Res., 103, 7767-7786, doi:10.1029/97JC01911.

$\longrightarrow, \ldots$, and J. Tournadre, 2010: Satellite microwave surface observations in tropical cyclones. Mon. Wea. Rev., 138, 421-437, doi:10.1175/2009MWR3040.1.
Raizer, V., 2007: Macroscopic foam-spray models for ocean microwave radiometry. IEEE Trans. Geosci. Remote Sens., 45, 3138-3144, doi:10.1109/TGRS.2007.895981.

Reasor, P. D., M. T. Montgomery, and L. D. Grasso, 2004: A new look at the problem of tropical cyclones in vertical shear flow: Vortex resiliency. J. Atmos. Sci., 61, 3-22, doi:10.1175/1520-0469(2004)061<0003:ANLATP $>2.0 . \mathrm{CO} ; 2$.

Reul, N., and B. Chapron, 2003: A model of sea-foam thickness distribution for passive microwave remote sensing applications. J. Geophys. Res., 108, 3321, doi:10.1029/2003JC001887.

—, J. Tenerelli, B. Chapron, D. Vandermark, Y. Quilfen and Y. Kerr, 2012: SMOS satellite L-band radiometer: A new capability for ocean surface remote sensing in hurricanes. J. Geophys. Res., 117, C02006, doi:10.1029/2011JC007474.

—, B. Chapron, E. Zabolotskikh, C. Donlon, Y. Quilfen, S. Guimbard, and J. F. Piolle, 2016: A revised L-band radio-brightness sensitivity to extreme winds under tropical cyclones: The five year SMOS-storm database. Remote Sens. Environ., 180, 274-291, doi:10.1016 /j.rse.2016.03.011.

Ross, D. B., and V. Cardone, 1974: Observations of oceanic whitecaps and their relation to remote measurements of surface wind speed. J. Geophys. Res., 79, 444-452, doi:10.1029/JC079i003p00444.

Rozoff, C. M., D. S. Nolan, J. P. Kossin, F. Zhang, and J. Fang, 2012: The roles of an expanding wind field and inertial stability in tropical cyclone secondary eyewall formation. J. Atmos. Sci., 69, 2621-2643, doi:10.1175/JAS-D-11-0326.1.

Saitoh, S., and A. Shibata, 2010: AMSR-E all weather sea surface wind speed (in Japanese). Tenki, 57, 5-18. [Available online at www.metsoc.jp/tenki /pdf/2010/2010_01_0005.pdf.]

Sampson, C. R., and A. J. Schrader, 2000: The Automated Tropical Cyclone Forecasting System (version 3.2). Bull. Amer. Meteor. Soc., 81, 1231-1240, doi:10.1175/15200477(2000)081<1231:TATCFS>2.3.CO;2.

— tropical cyclone gale wind radii. Wea. Forecasting, 30, 1397-1403, doi:10.1175/WAF-D-15-0009.1.

—, P. A. Wittmann, and H. L. Tolman, 2010: Consistent tropical cyclone wind and wave forecasts for the U.S. Navy. Wea. Forecasting, 25, 1293-1306, doi:10.1175/2010WAF2222376.1.

— , and Coauthors, 2012: Objective guidance for use in setting tropical cyclone conditions of readiness. Wea. Forecasting, 27, 1052-1060, doi:10.1175/WAFD-12-00008.1.

Shibata, S., 2006: A wind speed retrieval algorithm by combining 6 and $10 \mathrm{GHz}$ data from Advanced 
Microwave Scanning Radiometer: Wind speed inside hurricanes. J. Oceanogr., 62, 351-359, doi:10.1007 /s10872-006-0060-8.

Soisuvarn, S., Z. Jelenak, P. S. Chang, S. O. Alsweiss, and Q. Zhu, 2013: CMOD5.H-A high wind geophysical model function for C-band vertically polarized satellite scatterometer measurements. IEEE Trans. Geosci. Remote Sens., 51, 3744-3760, doi:10.1109 /TGRS.2012.2219871.

Tallapragada, V., and Coauthors, 2014: Hurricane Weather Research and Forecasting (HWRF) model: 2014 scientific documentation. Developmental Testbed Center, 105 pp. [Available online at www.dtcenter .org/HurrWRF/users/docs/scientific_documents /HWRFv3.6a_ScientificDoc.pdf.]

Uhlhorn, E. W., P. G. Black, J. L. Franklin, M. Goodberlet, J. Carswell, and A. S. Goldstein, 2007: Hurricane surface wind measurements from an operational stepped frequency microwave radiometer. Mon. Wea. Rev., 135, 3070-3085, doi:10.1175/MWR3454.1.

Van Zadelhoff, G.-J., A. Stoffelen, P. W. Vachon, J. Wolfe, J. Horstmann, and M. Belmonte Rivas, 2014: Retrieving hurricane wind speeds using cross-polarization C-band measurements. Atmos. Meas. Tech., 7, 437449, doi:10.5194/amt-7-437-2014.

Velden, C., and Coauthors, 2006: The Dvorak tropical cyclone intensity estimation technique: A satellitebased method that has endured for over 30 years. Bull. Amer. Meteor. Soc., 87, 1195-1210, doi:10.1175 /BAMS-87-9-1195.

Webster, W. J., T. T. Wilheit, D. B. Ross, and P. Gloersen, 1976: Spectral characteristics of the microwave emission from a wind-driven foam covered sea. J. Geophys. Res., 81, 3095-3099, doi:10.1029/JC081i018p03095.

Weissman, D. E., M. A. Bourassa, and J. Tongue, 2002: Effects of rain rate and wind magnitude on sea winds scatterometer wind speed errors. J. Atmos. Oceanic Technol., 19, 738-746, doi:10.1175/1520-0426 (2002)019<0738:EORRAW>2.0.CO;2.

Wentz, F. J., C. Gentemann, D. Smith, and D. Chelton, 2000: Satellite measurements of sea surface temperature through clouds. Science, 288, 847-850, doi:10.1126/science.288.5467.847.

$\mathrm{Xu}$, J., and Y. Wang, 2010: Sensitivity of the simulated tropical cyclone inner-core size to the initial vortex size. Mon. Wea. Rev., 138, 4135-4157, doi:10.1175 /2010MWR3335.1.

- , and — 2015: A statistical analysis on the dependence of tropical cyclone intensification rate on the storm intensity and size in the North Atlantic. Wea. Forecasting, 30, 692-701, doi:10.1175/WAF -D-14-00141.1.

Young, I. R., 2003: A review of the sea state generated by hurricanes. Mar. Struct., 16, 201-218, doi:10.1016 /S0951-8339(02)00054-0.

__, and J. Vinoth, 2013: An "extended fetch" model for the spatial distribution of tropical cyclone windwaves as observed by altimeter. Ocean Eng., 70, 14-24, doi:10.1016/j.oceaneng.2013.05.015.

Yueh, S. H., 2008: Directional signals in WindSat observations of hurricane ocean winds. IEEE Trans. Geosci. Remote Sens., 46, 130-136, doi:10.1109 /TGRS.2007.909079.

—, A. G. Fore, W. Tang, A. Hayashi, B. Stiles, N. Reul, Y. Weng, and F. Zhang, 2016: SMAP L-band passive microwave observations of ocean surface wind during severe storms. IEEE Trans. Geosci. Remote Sens., 54, 7339-7350, doi:10.1109/TGRS .2016 .2600239 .

Zabolotskikh, E. V., L. M. Mitnik, and C. Bertrand, 2013: New approach for severe marine weather study using satellite passive microwave sensing. Geophys. Res. Lett., 40, 3347-3350, doi:10.1002/grl.50664.

,$- \ldots$, and ——, 2014: GCOM-W1 AMSR2 and MetOp-A ASCAT wind speeds for the extratropical cyclones over the North Atlantic. Remote Sens. Environ., 147, 89-98, doi:10.1016/j.rse.2014.02.016.

,-- , N. M. Reul, and B. Chapron, 2015: New possibilities for geophysical parameter retrievals opened by GCOM-W1 AMSR2. IEEE J. Sel. Top. Appl. Earth Obs. Remote Sens., 8, 4248-4261, doi:10.1109 /JSTARS.2015.2416514.

,-- , and — 2016: Geophysical model function for the AMSR2 C-band wind excess emissivity at high winds. IEEE Geosci. Remote Sens. Lett., 13, 78-81, doi:10.1109/LGRS.2015.2497463.

Zhang, L., X.-B. Yin, H.-Q. Shi, and Z.-Z. Wang, 2016: Hurricane wind speed estimation using WindSat 6 and $10 \mathrm{GHz}$ brightness temperatures. Remote Sens., 8, 721, doi:10.3390/rs8090721. 


\section{LOOKING FOR AN EXPERT?}

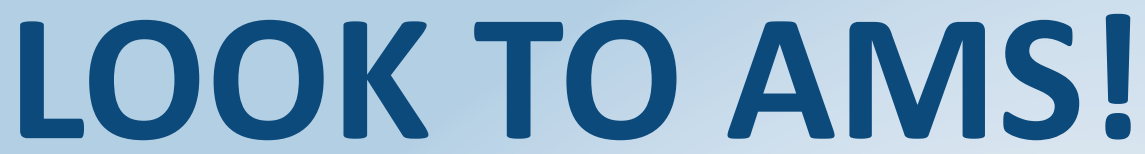

\section{AMS announces the launch of our new online directory of Weather and Climate Service Providers.}

This new online directory replaces the former BAMS Professional Directory and lists an array of weather and climate service providers. You can find the new directory under the "Find an Expert" link from the AMS home page.

It's easier than ever for the weather, water, and climate community and the general public to search for organizations and individuals offering these important services.

\section{Learn more at www.ametsoc.org}
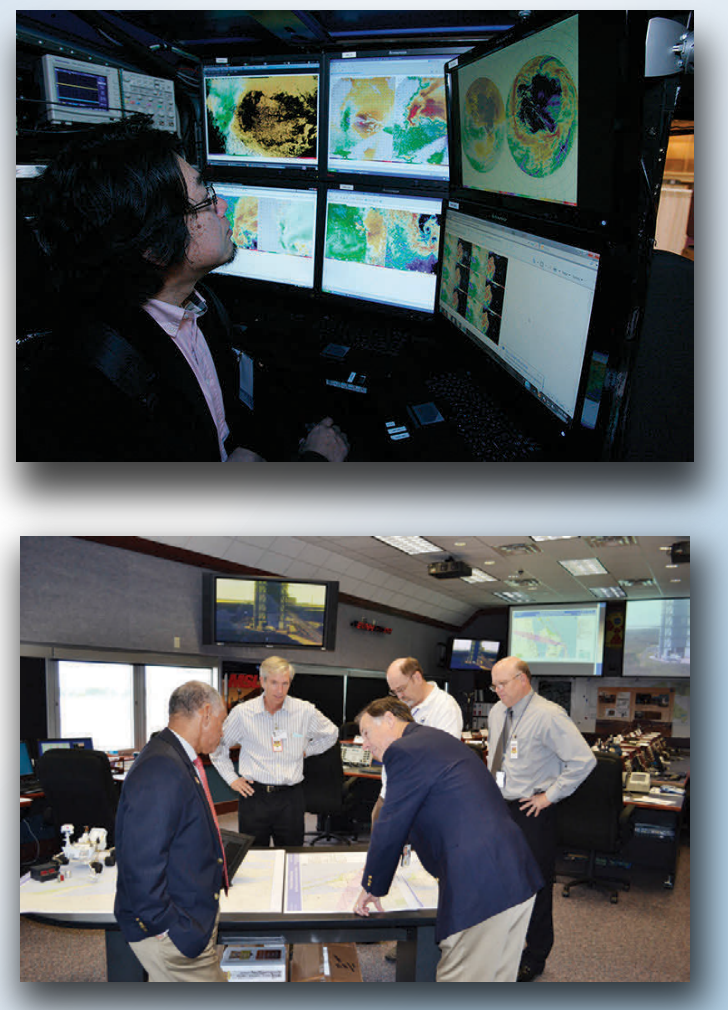

\section{NEW!}

\section{Weather \& Climaite Service Providers Directory}

